Acta Protozool. (2020) 59: 39-53

www.ejournals.eu/Acta-Protozoologica doi:10.4467/16890027AP.20.003.12159

PROTOZOOLOGICA

Research Article

\title{
Molecular Characterization of Two Myxosporean Species, Henneguya namae Haldar et al. 1983 and Myxobolus sophorae Jayasri, 1982 (Myxosporea: Myxobolidae)
}

\author{
Anupma GARG, Anshu CHAUDHARY, Abhishek GUPTA, Abhinav KUMAR, Bindu SHARMA, \\ Hridaya Shanker SINGH
}

Molecular Taxonomy Laboratory, Department of Zoology, Chaudhary Charan Singh University, Meerut (U.P.), India-250004

\begin{abstract}
In Indian freshwater fish myxosporean infections are among the most cosmopolitan parasites, they are relatively well studied morphologically but their phylogenetic relationships were unclear and the genetic data is limited only to a few species. The study aims to present molecular data for two myxosporean species, Henneguya namae Haldar et al. 1983 and Myxobolus sophorae Jayasri, 1982 collected from Indian freshwater fish, the elongate glass-perchlet Chanda nama (=Ambassis nama) and pool barb Puntius sophore, respectively. In the present study molecular data are provided for H. namae and $M$. sophorae using nested PCR. The obtained partial 18S rDNA gene sequences were analyzed using maximum likelihood (ML) and Bayesian inference (BI) methods. The 18S rDNA gene sequences of $H$. namae showed similarity with the sequences of $H$. chaudhuryi, Henneguya sp. RA-2015, H. voronini and $H$. setiuensis about 72.1 to $78 \%$ and $M$. sophorae with Myxobolus ticto was about $90 \%$ respectively. The aim of this paper was to identify H. namae and M. sophorae morphologically and using molecular methods.
\end{abstract}

Keywords: fish, Henneguya, India, Myxobolus, phylogeny, 18S rDNA.

\section{INTRODUCTION}

Myxozoans are a diverse group of endoparasites inhabiting vertebrates generally fish, sometimes amphibians and mammals also (Okamura et al. 2015). In Indian fish, more than 23 species of Henneguya and about 130 Myxobolus species has been reported from freshwater habitats, mostly were described on the basis of myxo-

Address for correspondence: Hridaya Shanker Singh, Molecular Taxonomy Laboratory, Department of Zoology, Chaudhary Charan Singh University, Meerut (U.P.), India-250004; Email: singhccsu0520@gmail.com spore shape and size morphology (Eiras 2002, Eiras et al. 2005, Kalavati and Nandi 2007, Kaur and Singh 2011, Eiras et al. 2014) and this number of species is going on increasing continuously (Székely et al. 2015, Gupta and Kaur 2017, Chaudhary et al. 2018, Ahmed et al. 2019). From India to the date, molecular sequences of 56 Myxobolus and 7 Henneguya species have been deposited in the GenBank. Recently, frequent occurrence of fish myxospores hastened us to investigate their diversity and infection in the present study area.

Chanda nama Hamilton, 1822 and Puntius sophore (Hamilton, 1822) distributes throughout Pakistan, India, Nepal, Bangladesh and Myanmar, also contributes 
significantly to the nutritional as well as the livelihood security of the rural mass. Both the fish have high economic value as these are appropriate for supplementing the part of diets among the developed and developing countries and also of ornamental value (Roos et al. 2003, Mohanty et al. 2013, Choudhary et al. 2015). In India, species of myxobolids were focused only based on spore morphology (Kalavati and Nandi 2007) and sometimes hard to discriminate between closely related species, therefore, molecular approaches are needed for correct identification.

In the present work, morphological redescription and molecular biological examinations of H. namae and M. sophorae were performed to support their validity.

\section{MATERIALS AND METHODS}

\section{Specimens and morphological analysis}

A total of 40 and 34 specimens of elongate glassy perchlet Chanda nama (=Ambassis nama) Hamilton, 1822 (Actinopterygii: Ambassidae) and pool barb Puntius sophore (Hamilton, 1822) (Actinopterygii: Cyprinidae) were collected respectively from the Ganga River at Bairaj, Bijnor (29 $23^{\prime}$ N, $79^{\circ} 11^{\prime}$ E) from the local vendors that collected fish and from local fishermen in Meerut $\left(29^{\circ}\right.$ $01^{\prime} \mathrm{N}, 77^{\circ} 45^{\prime} \mathrm{E}$ ), in the state of Uttar Pradesh (U.P.), India during the period between October 2018 to February 2019. They were transported in icebox to the laboratory at the Department of Zoology, Chaudhary Charan Singh University, Meerut, U.P., India for routine parasitological examination. Fish were euthanized by clove oil, fresh preparations of kidney, liver, gill filaments, gall bladder and muscles were examined for myxozoan infection under a Motic SMZ-168 series stereomicroscope (Motic, Xiamen, People's Republic of China). Infection was found in the gill filaments and kidney of C. nama and P. sophore respectively. Cysts from the gill filaments of C. nama and plasmodia within kidney tissue of $P$. sophore was examined as fresh preparations under a Nikon eclipse Ts 2 microscope (Nikon Corporation, Tokyo, Japan) for morphology of the spores. A subset was fixed in $95 \%$ ethanol for subsequent molecular study. Photographs of the spores were taken with a Nikon eclipse (Ts2) microscope using Nikon NIS Elements Imaging software version 5.10. Measurements of fresh myxospores were taken according to the guidelines of Lom and Arthur (1989). All measurements reported here are in micrometers $(\mu \mathrm{m})$ unless stated otherwise. Photos of spores were deposited in the Museum, Department of Zoology, Chaudhary Charan Singh University, Meerut (U.P.), India (Coll. No. HSS/ZOO/MYX/01/19 and HSS/ZOO/MYX/02/19).

\section{PCR and DNA sequencing}

For DNA extraction, preserved sample in $95 \%$ ethanol were centrifuged at $8,000 \times g$ for $5 \mathrm{~min}$ and then the ethanol was removed. Genomic DNA was extracted using the Qiagen DNeasy ${ }^{\mathrm{TM}}$ Blood \& Tissue Kit (Qiagen, Germany), following the manufacturer's protocol. The partial $18 \mathrm{~S}$ rDNA was amplified using the primers ERIB1 and ERIB10 (Table 1) in a $25 \mu$ reaction mixture comprising $3 \mu \mathrm{l}$ genomic DNA, $4 \mu \mathrm{l} 1 \mathrm{mM}$ deoxyribonucleotide triphosphates (dNTPs, Biotools, Spain), $0.50 \mu$ of each primer, 2.5 $\mu \mathrm{l}$ of $10 \times$ Taq buffer (Biotools, Spain), $0.50 \mu \mathrm{l}$ of Taq polymerase ( $1 \mathrm{U}$; Biotools, Spain), and $14 \mu \mathrm{l}$ of distilled water. The PCR cycle consisted of an initial denaturation step at $95{ }^{\circ} \mathrm{C}$ for $3 \mathrm{~min}$, followed by 35 cycles of at $95{ }^{\circ} \mathrm{C}$ for $50 \mathrm{~s}, 56{ }^{\circ} \mathrm{C}$ for $1 \mathrm{~min}, 72{ }^{\circ} \mathrm{C}$ for $1 \mathrm{~min}$ and a final extension at $72{ }^{\circ} \mathrm{C}$ for $7 \mathrm{~min}$. This was followed by a second round of PCR with the Myx1F-SphR primer pair (Table 1). A total volume of the reaction was $50 \mu \mathrm{l}$, containing $2 \mu \mathrm{l}$ of amplified DNA, $0.8 \mu \mathrm{l}$ of each primer, $5 \mu \mathrm{l}$ of $10 \times$ Taq buffer (Biotools, Spain), $10 \mu \mathrm{l}$ of the $1 \mathrm{mM}$ dNTPs (Biotools, Spain), $0.9 \mu 1$ of Taq polymerase (1 U; Biotools, Spain) and $30.5 \mu 1$ of distilled water. PCR amplification protocol for the second round as follows: $95^{\circ} \mathrm{C}$ for $3 \mathrm{~min}$, then 35 cycles at $95^{\circ} \mathrm{C}$ for $50 \mathrm{~s}, 56^{\circ} \mathrm{C}$ for $1 \mathrm{~min}, 72^{\circ} \mathrm{C}$ for $1 \mathrm{~min}$, terminated with an extension at $72{ }^{\circ} \mathrm{C}$ for $10 \mathrm{~min}$ and then resting at $4{ }^{\circ} \mathrm{C}$. The obtained PCR products were electrophoresed, separated by $1 \%$ agarose gel in Tris-acetate-EDTA buffer stained with $1 \%$ ethidium bromide and observed under ultraviolet light. They were then purified with a Purelink ${ }^{\mathrm{TM}}$ Quick Gel Extraction and PCR Purification Combo Kit (Invitrogen, Löhne, Germany). Then purified PCR products were sequenced with the primers listed in Table 1, with the ABI Big Dye Terminator v3.1 Cycle Sequencing Kit in ABI 3100 Genetic Analyzer, Applied Biosystems (Foster City, California, USA).

\section{DNA sequence analyses}

Sequences from closely related myxozoans were found out by BLASTn search and downloaded for further analysis. Sequences were aligned in BioEdit (Hall 1999) and ambiguous bases clarified using corresponding ABI chromatograms. For phylogenetic relationships of the present species with the related myxozoans, sequences retrieved from GenBank were aligned using the Clustal W program (Thompson et al. 1994) with defaulting setting, implementing in MEGA7 (Kumar et al. 2016). Phylogenetic analysis was conducted using maximum likelihood (ML) analysis performed in MEGA7 (Kumar et al. 2016) and Bayesian analyses were conducted in Topali 2.5 (Milne et al. 2009). For maximum likelihood (ML) and Bayesian analysis, the best evolutionary model was determined by jModelTest 3.0 (Posada 2008) which identified the general time reversible model $(\mathrm{GTR}+\mathrm{I}+\mathrm{G})$ as the best evolutionary model, using Akaike information criteria. DNA pairwise sequence distances were calculated using the p-distance model in MEGA7. Bootstrap values based on 1,000 resampled datasets were generated for ML. For Bayesian inference (BI) analyses, posterior probabilities were estimated over 1,000,000 generations via five independent runs of four simultaneous MCMCMC (Metropolis-coupled Markov chain Monte Carl) chains with every 100th tree saved. The "burn in" was set to $25 \%$. Myxobolus cerebralis (MN266293) was designated as outgroup.

\section{RESULTS}

\section{Henneguya namae Haldar et al. 1983}

Type host: Chanda nama (=Ambassis nama) Hamilton, 1822; chanda (local name). 
Table 1. Primers used for PCR and sequencing in the present study.

\begin{tabular}{llll}
\hline Primer & Sequence $\left(5^{\prime}-3^{\prime}\right)$ & Application & Source \\
\hline ERIB1 & ACCTGGTTGATCCTGCCAG & 1st round PCR & Barta et al. 1997 \\
ERIB10 & CTTCCGCAGGTTCACCTACGG & 1st round PCR & Barta et al. 1997 \\
Myx1F & GTGAGACTGCGGACGGCTCAG & 2nd round PCR and sequencing & Hallet and Diamant 2001 \\
SphR & GTTACCATTGTAGCGCGCGT & 2nd round PCR and sequencing & Eszterbauer and Székely 2004 \\
MC5 & CCTGAGAAACGGCTACCACATCCA & Sequencing & Molnár et al. 2002 \\
MC3 & GATTAGCCTGACAGATCACTCCACGA & Sequencing & Molnár et al. 2002 \\
ACT1r & AATTTCACCTCTCGCTGCCA & Sequencing & Hallet and Diamant 2001 \\
\hline
\end{tabular}

Site of infection: Gill filaments.

Locality: Ganga River at Bairaj, Bijnor (29 23' N, $79^{\circ} 11^{\prime} \mathrm{E}$ ) in the state of Uttar Pradesh (U.P.), India.

Prevalence of infection: A total of 40 specimens of Chanda nama shows prevalence of infection 34/40 (of the 5-6 cm size in length with a prevalence of $85 \%$; Intensity of infection: High).

Material deposited: Digital images (Photos) of spores were deposited in the parasitological collection of the Museum, Department of Zoology, Chaudhary Charan Singh University, Meerut (U.P.), India collection no. (Coll. No. HSS/ZOO/MYX/01/19). The $18 \mathrm{~S}$ rDNA sequence was deposited in GenBank under accession numbers MN218392 and MN218393.

Description: $H$. namae cyst present in the lamellae of gill filaments roundish in shape, interlamellar measuring 70-150 $\mu \mathrm{m}$, small and large due to synchronicity development and contained myxospores that clearly showed high infection (Fig. 1 A, B). Spore body elongated with two caudal appendages (Fig. 1 C, D; Fig. 2 A, B). In frontal view, anterior end of spores appears blunt while the caudal end somewhat rounded and gradually continued into long, bifurcated caudal appendages (Fig. 2 A, B). Total spores length, 27.82-33.17 (30.6 \pm 1.71$)$ $(\mathrm{N}=30)$; spore body length, $12.34-15.6(14.15 \pm 0.96)$ $(\mathrm{N}=30)$; caudal appendages length, 15.12-17.92 $(16.64 \pm 1.03)(\mathrm{N}=30)$; spore width, 4.94-5.98 (5.41 $\pm 0.32)(\mathrm{N}=30)$ and spore thickness, 3.9-4.34 (4.07 $\pm 0.15)(\mathrm{N}=20)$. Spore wall smooth, composed of two uniformly thin valves, sutural line prominent and thick. Polar capsule two in number, elongated, pear shaped, pointed at anterior end and unequal in size. Larger capsule 3.18-4.16 $(3.66 \pm 0.34)(\mathrm{N}=30)$ long and 1.0-1.14 $(1.08 \pm 0.05)(\mathrm{N}=15)$ wide. Smaller capsule $2.84-3.73$ $(3.27 \pm 0.31)(\mathrm{N}=30)$ long and $0.98-1.1(1.04 \pm 0.04)$ $(\mathrm{N}=15)$ wide. Number of polar filament coils seen 8-9 in large and 6-7 in small one. H. namae was identified on basis of the above characteristics. All the mor- phometrical measurements with closely related species listed in the supplementary table 1 .

Remarks: H. namae was compared with other Henneguya spp. described parasitizing freshwater fish. Originally $H$. namae was described by Haldar et al. 1983 from gills of C. nama. Approximately $>20$ species described thus far in Indian fish, the spores of H. namae infecting the gills of $C$. nama revealed the greatest similarity to the spores of $H$. ophiocephali Chakravarty 1939, H. notopterae Lalitha Kumari 1965, H. qadrii Qadri 1965, H. singhi Lalita Kumari 1969 and H. thermalis Seenappa et al. 1981. Moreover, the strict morphological comparisons showed that the shape, size of spore body and the length of caudal appendage of above respective species can be easily differentiated $H$. namae from others (Supplementary table 1). In the Supplementary table 1, we add Henneguya species reported from India that was similar to $H$. namae and shows species with unequal polar capsules i.e., H. ophiocephali, $H$. notopterae, $H$. qadrii, $H$. singhi and $H$. thermalis. $H$. namae could be distinguished from $H$. ophiocephali in the size and shape of the spore body as it is more rounded anteriorly in $H$. ophiocephali. $H$. notopterae have more pointed at the anterior end in spore shape in comparison to $H$. namae and additionally with a long duct in polar capsule. Spores of $H$. qadrii are smaller in size as compared to $H$. namae but size of polar capsules of $H$. qadrii is larger as compared to $H$. namae. Moreover, the spore body of $H$. namae is more elongated as compare to $H$. singhi as well as distinguished with each other in polar capsule shape. However, H. thermalis have a more rounded shape of spores while H. namae have little roundish and more pointed, both differ in the shape and size of polar capsules too. With regard to H. chaudhuryi (Bajpai and Haldar 1982) and Henneguya sp. RA-2015 (KR704889) Bala (2015), the differences are the presence of equal polar capsules while $H$. namae comprise unequal polar capsules. There are 

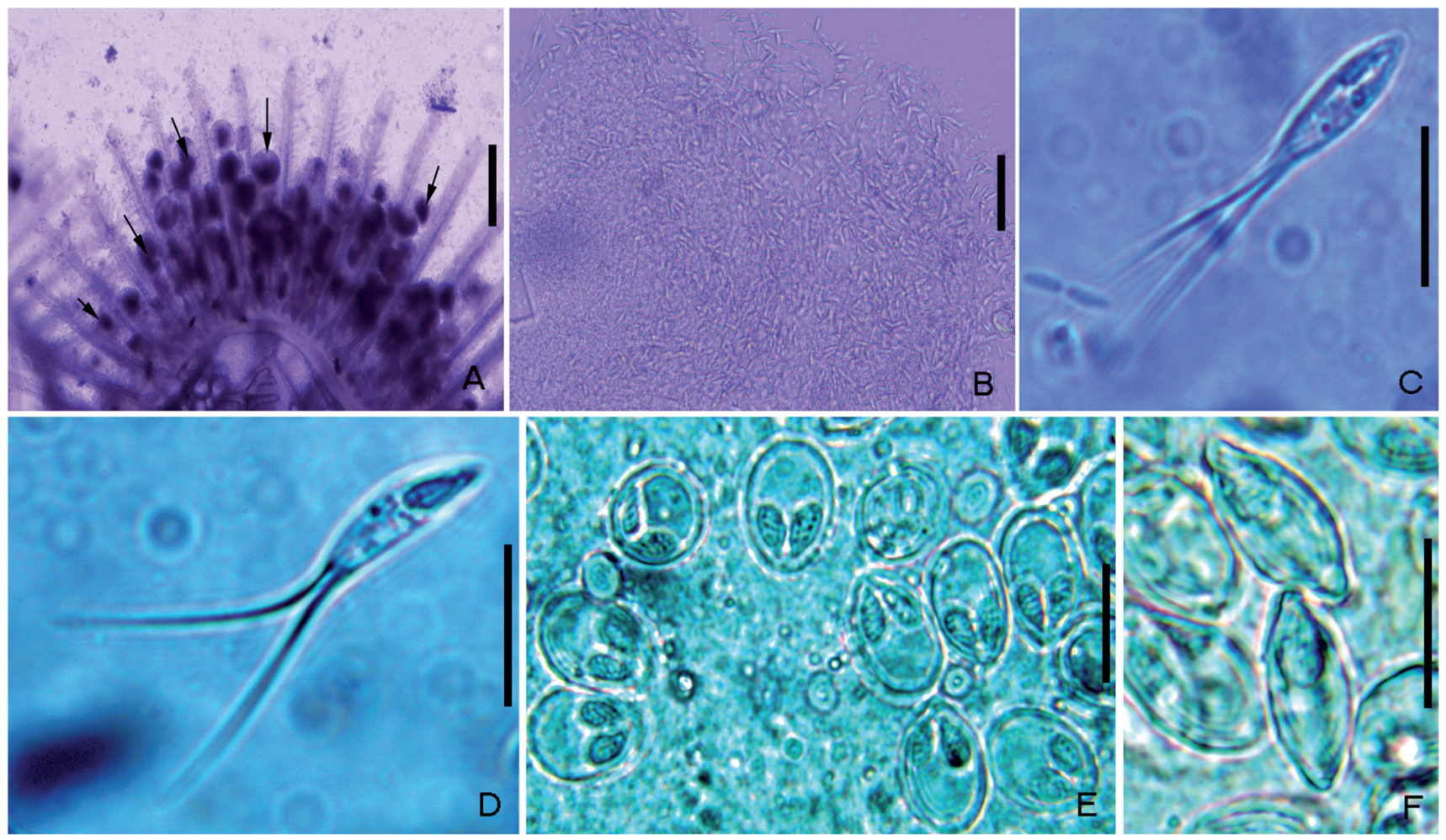

Fig. 1. Photographs of myxobolids: A - Cysts of H. namae of different sizes between gill filaments of the host fish show by arrows, $\mathrm{B}$ - Spores released from ruptured cysts of $H$. namae, $\mathrm{C}-H$. namae frontal view, $\mathrm{D}-H$. namae sutural view, $\mathrm{E}-\mathrm{M}$. sophorae frontal view, F-M. sophorae sutural view. Scale bars (A) $300 \mu \mathrm{m}$, (B) $50 \mu \mathrm{m},(\mathrm{C}-\mathrm{F}) 10 \mu \mathrm{m}$.

no molecular data available for the species $H$. ophiocephali, H. notopterae, H. qadrii, H. singhi and H. thermalis. Therefore, on the basis of above mentioned characteristics of $H$. namae, it can be readily distinguished from other species (see in supplementary table 1).

Molecular analysis: 18S rDNA of two different pools of isolates of $H$. namae were sequenced (1305 and $1315 \mathrm{bp}$ ). No intraspecific divergence was found among the newly generated sequences from isolates of $H$. namae and shown to be closely related with other Henneguya species described from Perciformes and Cypriniformes hosts.

\section{Myxobolus sophorae Jayasri, 1982}

Type host: Puntius sophore (Hamilton, 1822); punti (local name).

Site of infection: Kidney.

Locality: Meerut $\left(29^{\circ} 01^{\prime} \mathrm{N}, 77^{\circ} 45^{\prime} \mathrm{E}\right)$, in the state of Uttar Pradesh (U.P.), India.

Prevalence of infection: A total of 34 specimems of Puntius sophore shows prevalence of infection: 11/34 (of the 5-6 cm size in length with a prevalence of $32 \%$; Intensity of infection: Low) during the present study.

Material deposited: Digital images (Photos) of spores were deposited in the parasitological collection of the Museum, Department of Zoology, Chaudhary Charan Singh University, Meerut (U.P.), India collection no. (Coll. No. HSS/ZOO/MYX/02/19). The 18S rDNA sequence was deposited in GenBank under accession numbers MN595207 and MN595208.

Description: Plasmodia filled with spores and scattered spores were found in the kidneys. Spores ovorounded shaped in frontal view, anterior and posterior ends blunt, anterior end narrower than the posterior end (Fig. 1 E, F; Fig. 2 C, D). Spore length 14.0-15.1 $(14.57 \pm 0.33)(\mathrm{N}=30)$; width, $10.4-11.4(10.91 \pm 0.34)$ $(\mathrm{N}=30)$ and thickness, 6.2-7.4 $(6.91 \pm 0.35)(\mathrm{N}=20)$. Polar capsules two in number, pyriform in shape and slightly unequal in size, obliquely located on either side of the midline, filling around half of the spore cavity. Larger capsule length 5.72-6.5 $(6.04 \pm 0.27)(\mathrm{N}=30)$ and width, 2.6-3.2 $(2.89 \pm 0.22)(\mathrm{N}=30)$. Smaller cap- 

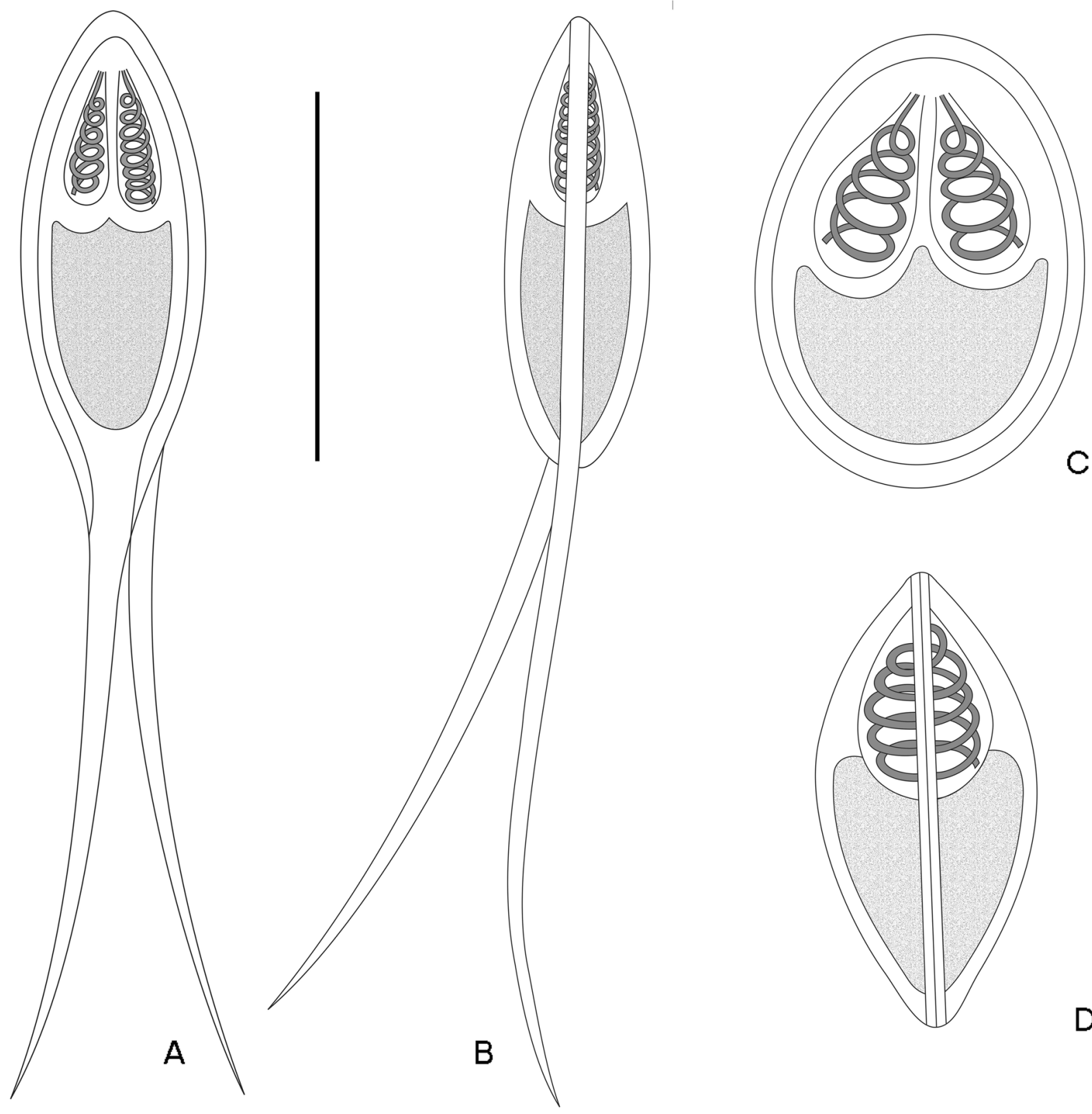

D

Fig. 2. A schematic drawing of Henneguya namae and Myxobolus sophorae myxospores found infect Chanda nama and Puntius sophore. In frontal view: A - H. namae, $\mathrm{C}-M$. sophorae. In sutural view: $\mathrm{B}-H$. namae, $\mathrm{D}-$ M. sophorae. Scale bars $(\mathrm{A}-\mathrm{D}) 10 \mu \mathrm{m}$.

sule length 4.94-6.14 $(5.48 \pm 0.34)(\mathrm{N}=30)$ and width, 2.34-3.12 (2.69 \pm 0.24$)(\mathrm{N}=30)$. Polar capsules open to exterior of spores on either side of midline pointing towards each other, equipped with polar filaments which are distinctly seen. Number of filament coils seen is 5-6 in both the polar capsules, polar filament threadlike and uniform in their thickness throughout the length. $M$. sophorae identified morphologically on the basis of above described characteristics and the details of morphometrical data of $M$. sophorae with other related species are presented in supplementary table 2 .

Remarks: This species was originally described from the gills and kidney of $P$. sophore by Jaysari, 1982. Myxospores of $M$. sophorae differentiated from the other species that infected host of the genus Puntius from India based on morphology and morphometrics 


\section{A. Garg et al.}

Table 2. Pairwise distance (above diagonal) and identity values (below diagonal) among myxozoan species of the ribosomal $18 \mathrm{~S}$ gene sequences.

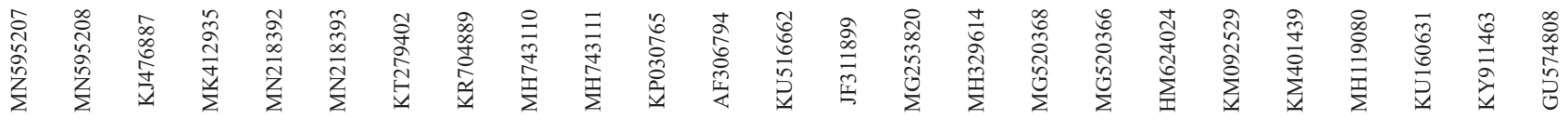

\begin{tabular}{lllllllllllllllllllllllll}
\hline MN595207 & 0.00 & 0.07 & 0.27 & 0.41 & 0.41 & 0.29 & 0.39 & 0.27 & 0.28 & 0.18 & 0.30 & 0.25 & 0.22 & 0.18 & 0.16 & 0.17 & 0.17 & 0.17 & 0.17 & 0.17 & 0.18 & 0.15 & 0.19 & 0.18
\end{tabular} $\begin{array}{lllllllllllllllllllllllllll}\text { MN595208 } & 100 & 0.07 & 0.27 & 0.41 & 0.41 & 0.29 & 0.39 & 0.27 & 0.28 & 0.18 & 0.30 & 0.25 & 0.22 & 0.18 & 0.16 & 0.17 & 0.17 & 0.17 & 0.17 & 0.17 & 0.18 & 0.15 & 0.19 & 0.18\end{array}$ $\begin{array}{llllllllllllllllllllllllll}\text { KJ476887 } & 90 & 90 & 0.29 & 0.37 & 0.37 & 0.29 & 0.34 & 0.28 & 0.31 & 0.13 & 0.28 & 0.21 & 0.20 & 0.15 & 0.12 & 0.13 & 0.13 & 0.12 & 0.15 & 0.13 & 0.14 & 0.15 & 0.15 & 0.14\end{array}$ $\begin{array}{lllllllllllllllllllllllllll}\text { MK412935 } & 68.9 & 68.9 & 68.2 & 0.42 & 0.42 & 0.38 & 0.39 & 0.36 & 0.36 & 0.26 & 0.36 & 0.33 & 0.30 & 0.27 & 0.26 & 0.26 & 0.26 & 0.27 & 0.27 & 0.27 & 0.26 & 0.27 & 0.24 & 0.24\end{array}$ $\begin{array}{llllllllllllllllllllllllllll}\text { MN218392 } & 53.1 & 53.1 & 56.5 & 50.9 & 0.00 & 0.21 & 0.23 & 0.24 & 0.24 & 0.36 & 0.31 & 0.35 & 0.34 & 0.36 & 0.36 & 0.35 & 0.36 & 0.36 & 0.36 & 0.37 & 0.36 & 0.35 & 0.36 & 0.36\end{array}$ $\begin{array}{llllllllllllllllllllllllllll}\text { MN218393 } & 53.1 & 53.1 & 56.5 & 50.9 & 100 & 0.21 & 0.23 & 0.24 & 0.24 & 0.36 & 0.31 & 0.35 & 0.34 & 0.36 & 0.36 & 0.35 & 0.36 & 0.36 & 0.36 & 0.37 & 0.36 & 0.35 & 0.36 & 0.36\end{array}$

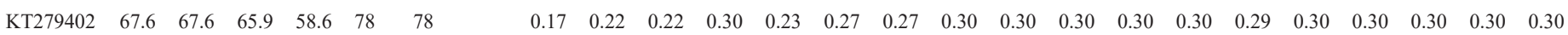
$\begin{array}{llllllllllllllllllllllllllll}\text { KR704889 } & 57.7 & 57.7 & 61.7 & 56.1 & 76.4 & 76.4 & 80.6 & 0.26 & 0.25 & 0.34 & 0.27 & 0.34 & 0.32 & 0.34 & 0.34 & 0.34 & 0.34 & 0.34 & 0.32 & 0.34 & 0.33 & 0.34 & 0.33 & 0.34\end{array}$ $\begin{array}{llllllllllllllllllllllllll}\text { MH743110 } & 70.3 & 70.3 & 67.8 & 60.8 & 72.1 & 72.1 & 74 & 69.5 & 0.13 & 0.29 & 0.23 & 0.27 & 0.27 & 0.29 & 0.29 & 0.29 & 0.29 & 0.29 & 0.28 & 0.28 & 0.28 & 0.27 & 0.28 & 0.28\end{array}$ $\begin{array}{llllllllllllllllllllllllllll}\text { MH743111 } & 68.8 & 68.8 & 64.4 & 60.6 & 72.7 & 72.7 & 73.6 & 70.2 & 85 & 0.31 & 0.24 & 0.27 & 0.26 & 0.31 & 0.30 & 0.31 & 0.31 & 0.32 & 0.28 & 0.31 & 0.31 & 0.26 & 0.31 & 0.31\end{array}$ $\begin{array}{llllllllllllllllllllllllllll}\text { KP030765 } & 81.4 & 81.4 & 85 & 71.2 & 57.5 & 57.5 & 65.8 & 62.4 & 67.7 & 63.8 & 0.27 & 0.22 & 0.19 & 0.09 & 0.10 & 0.08 & 0.08 & 0.10 & 0.09 & 0.07 & 0.08 & 0.13 & 0.14 & 0.13\end{array}$ $\begin{array}{llllllllllllllllllllllllllll}\text { AF306794 } & 66.3 & 66.3 & 67.6 & 59 & 74.5 & 74.5 & 72.3 & 68.1 & 73.2 & 72.6 & 69.2 & 0.28 & 0.27 & 0.27 & 0.27 & 0.27 & 0.27 & 0.28 & 0.27 & 0.27 & 0.27 & 0.29 & 0.27 & 0.28\end{array}$ $\begin{array}{llllllllllllllllllllllllllll}\text { KU516662 } & 70.1 & 70.1 & 75 & 62.9 & 56.8 & 56.8 & 67.3 & 60.7 & 68.3 & 68.5 & 74.3 & 66.5 & 0.16 & 0.22 & 0.21 & 0.21 & 0.21 & 0.21 & 0.20 & 0.21 & 0.21 & 0.21 & 0.22 & 0.22\end{array}$ $\begin{array}{lllllllllllllllllllllllllll}\text { JF311899 } & 75.5 & 75.5 & 77.2 & 66.5 & 59.6 & 59.6 & 68.1 & 63.2 & 69.5 & 69.9 & 78.9 & 69.1 & 79.9 & 0.19 & 0.19 & 0.19 & 0.19 & 0.18 & 0.20 & 0.19 & 0.19 & 0.21 & 0.19 & 0.18\end{array}$ $\begin{array}{lllllllllllllllllllllllllll}\text { MG253820 } & 80.8 & 80.8 & 83.5 & 69.9 & 57 & 57 & 65.9 & 61.8 & 66.9 & 64.4 & 90.2 & 69 & 74.4 & 78.2 & 0.12 & 0.09 & 0.09 & 0.12 & 0.11 & 0.09 & 0.10 & 0.15 & 0.16 & 0.14\end{array}$ $\begin{array}{lllllllllllllllllllllllllll}\text { MH329614 } & 82.4 & 82.4 & 86 & 71 & 57.6 & 57.6 & 65.2 & 62.4 & 68.2 & 65.4 & 88.5 & 69 & 75.8 & 79.4 & 86.8 & 0.10 & 0.10 & 0.05 & 0.12 & 0.10 & 0.11 & 0.06 & 0.14 & 0.13\end{array}$ $\begin{array}{lllllllllllllllllllllllllll}\text { MG520368 } & 81.6 & 81.6 & 85 & 71 & 57.7 & 57.7 & 65.4 & 61.9 & 67.9 & 64.5 & 91.7 & 68.2 & 75.5 & 78.5 & 89.9 & 87.9 & & 0.03 & 0.11 & 0.10 & 0.08 & 0.05 & 0.12 & 0.14 & 0.13\end{array}$ $\begin{array}{lllllllllllllllllllllllllll}\text { MG520366 } & 81.5 & 81.5 & 85.1 & 71.6 & 57.3 & 57.3 & 65.9 & 61.5 & 67.6 & 64.2 & 91.2 & 68.3 & 75.7 & 78.6 & 89.6 & 87.7 & 96.9 & & 0.12 & 0.10 & 0.08 & 0.04 & 0.13 & 0.15 & 0.14\end{array}$ $\begin{array}{lllllllllllllllllllllllllll}\text { HM624024 } & 82.2 & 82.2 & 85.9 & 70.4 & 57.5 & 57.5 & 65.4 & 62.2 & 67.5 & 63.6 & 88.8 & 68 & 75.7 & 79.4 & 86.7 & 94.2 & 87.8 & 87.6 & 0.13 & 0.11 & 0.12 & 0.05 & 0.14 & 0.13\end{array}$ $\begin{array}{lllllllllllllllllllllllllll}\text { KM092529 } & 81.7 & 81.7 & 83.1 & 70.7 & 57.8 & 57.8 & 66.6 & 63.5 & 68.3 & 68.2 & 90.1 & 68.7 & 75.9 & 77.4 & 87.8 & 86.5 & 88.9 & 88.7 & 85.9 & 0.01 & 0.10 & 0.13 & 0.16 & 0.15\end{array}$ $\begin{array}{llllllllllllllllllllllllllll}\text { KM401439 } & 81.4 & 81.4 & 85 & 70.5 & 56.6 & 56.6 & 65.4 & 62.1 & 68.2 & 64.3 & 92.4 & 68.8 & 75.4 & 78.8 & 89.8 & 87.8 & 91.1 & 90.8 & 88.3 & 98 & & 0.09 & 0.13 & 0.14 & 0.13\end{array}$ $\begin{array}{llllllllllllllllllllllllll}\text { MH119080 } & 81 & 81 & 84.4 & 71 & 57.2 & 57.2 & 65.9 & 62.2 & 68.4 & 65.3 & 91.5 & 69.1 & 75.4 & 78.4 & 89.1 & 87.9 & 94.9 & 95.3 & 86.6 & 88.8 & 90.2 & 0.12 & 0.15 & 0.14\end{array}$ $\begin{array}{llllllllllllllllllllllllllll}\text { KU160631 } & 83.5 & 83.5 & 82.6 & 70.6 & 58.2 & 58.2 & 66.1 & 62.3 & 70.4 & 70.5 & 85.3 & 67.2 & 75.7 & 76.8 & 82.9 & 93.1 & 85.7 & 85.5 & 94.3 & 84.7 & 84.9 & 85.7 & & 0.17 & 0.16\end{array}$ $\begin{array}{llllllllllllllllllllllllllll}\text { KY911463 } & 79.7 & 79.7 & 82.8 & 74 & 57.2 & 57.2 & 65.7 & 63.1 & 68.4 & 63.9 & 84.3 & 68.5 & 74.2 & 78.1 & 82.8 & 83.6 & 84.6 & 84.1 & 84.4 & 83.2 & 84.3 & 83.4 & 81.7 & 0.06\end{array}$ $\begin{array}{llllllllllllllllllllllllllll}\text { GU574808 } & 80.6 & 80.6 & 83.9 & 74.2 & 57.4 & 57.4 & 66 & 62.6 & 68.6 & 64.6 & 84.6 & 68.6 & 74.7 & 79.1 & 84 & 85.2 & 84.5 & 84.2 & 84.5 & 83.4 & 84.4 & 84.3 & 82.6 & 92.7\end{array}$ $\begin{array}{lllllllllllllllllllllllllllll}\text { MK412938 } & 83.9 & 83.9 & 84.4 & 69.8 & 57.8 & 57.8 & 65.7 & 62.6 & 66.8 & 63.5 & 85.4 & 68.3 & 75.6 & 76.7 & 84.1 & 90.5 & 84.8 & 84.9 & 89.8 & 84.4 & 85.2 & 85 & 88.5 & 82.6 & 82.5\end{array}$ $\begin{array}{lllllllllllllllllllllllllllll}\mathrm{KJ} 725075 & 81.2 & 81.2 & 82.3 & 71.1 & 58 & 58 & 66.5 & 61.8 & 68.8 & 69.4 & 89.3 & 66.3 & 75.7 & 77.9 & 88.4 & 86.3 & 97 & 95.9 & 85.2 & 88.1 & 88.5 & 93.9 & 85.1 & 81.3 & 82.8\end{array}$ $\begin{array}{lllllllllllllllllllllllllllll}\text { HM146129 } & 80.4 & 80.4 & 83.5 & 74.3 & 57.5 & 57.5 & 66 & 63.1 & 68.3 & 64.5 & 85 & 68.5 & 74.3 & 79.1 & 83.8 & 84.6 & 85.1 & 84.6 & 85 & 83.7 & 85.3 & 84 & 82.2 & 94.3 & 95.8\end{array}$ $\begin{array}{lllllllllllllllllllllllllllll}\mathrm{MH} 329618 & 82.3 & 82.3 & 81.4 & 74.4 & 57.9 & 57.9 & 66.5 & 63.1 & 70.1 & 70.4 & 81.6 & 67 & 73.8 & 76.7 & 81 & 82.2 & 82.3 & 82 & 81.8 & 81.6 & 81.8 & 81.7 & 81.6 & 92.8 & 96\end{array}$ $\begin{array}{lllllllllllllllllllllllllllll}\text { KC843624 } & 80.6 & 80.6 & 84.8 & 71.2 & 57.5 & 57.5 & 66.6 & 62.4 & 68 & 64.7 & 88.1 & 69 & 75.1 & 78.3 & 86.4 & 91.2 & 88.1 & 88 & 91 & 85.3 & 87.2 & 87.3 & 88.3 & 84.2 & 84.2\end{array}$ $\begin{array}{llllllllllllllllllllllllllll}\text { MH119079 } & 81.2 & 81.2 & 84.7 & 70.5 & 56.7 & 56.7 & 65.3 & 61.8 & 68.2 & 65.3 & 91 & 69.1 & 75.3 & 78.9 & 89.5 & 88.2 & 95.1 & 95 & 87.3 & 88.7 & 90.3 & 95.8 & 85.2 & 83.6 & 84.9\end{array}$ $\begin{array}{llllllllllllllllllllllllllll}\text { MG520367 } & 81.5 & 81.5 & 84.9 & 71.4 & 56.8 & 56.8 & 66.2 & 61.9 & 67.7 & 64.2 & 91.2 & 68.9 & 75.4 & 79.5 & 89.7 & 88.1 & 95.1 & 94.9 & 88.3 & 88.9 & 91.1 & 94.3 & 85.9 & 84.3 & 84.5\end{array}$ $\begin{array}{lllllllllllllllllllllllllll}\text { AB447994 } & 66.5 & 66.5 & 68 & 59.1 & 75.5 & 75 & 74.9 & 69.4 & 71.5 & 68.5 & 69.7 & 75.5 & 67.1 & 68.3 & 68.8 & 69.2 & 69.3 & 69.3 & 69 & 67.9 & 69.1 & 69.9 & 67.9 & 69.3 & 69.3\end{array}$ $\begin{array}{lllllllllllllllllllllllllll}\text { AB447992 } & 66.6 & 66.6 & 68.1 & 59.4 & 75.1 & 75.1 & 75.3 & 69.2 & 71 & 68.3 & 70.1 & 75.2 & 66.8 & 68.7 & 69.3 & 69.3 & 69.6 & 69.4 & 69.2 & 68 & 69.2 & 69.9 & 68.2 & 69.7 & 69.8\end{array}$ $\begin{array}{llllllllllllllllllllllllllll}\text { AB447993 } & 66.6 & 66.6 & 68.6 & 59.3 & 75 & 75 & 72.6 & 68.4 & 72.4 & 70.1 & 69.8 & 75.5 & 67.5 & 69.5 & 69.9 & 70 & 69.3 & 69.2 & 69.6 & 68.7 & 69.4 & 70.3 & 68.3 & 68.7 & 69.7\end{array}$ $\begin{array}{llllllllllllllllllllllllllllll}\text { EU643628 } & 75.1 & 75.1 & 74.8 & 65 & 58.1 & 58.1 & 66.8 & 62.3 & 68.5 & 69.7 & 75.8 & 68.5 & 78.9 & 88.9 & 75.8 & 76.8 & 76.1 & 76.1 & 76.5 & 75.5 & 76 & 76.1 & 76.2 & 76.8 & 76.8\end{array}$ $\begin{array}{llllllllllllllllllllllllllll}\text { MK371243 } & 77.4 & 77.4 & 78.2 & 67.5 & 56.4 & 56.4 & 65.9 & 62.6 & 67 & 64.4 & 80.7 & 68.1 & 76.1 & 78.2 & 80.3 & 79.6 & 81.1 & 80.7 & 79.9 & 78.5 & 79.8 & 80.3 & 76.8 & 80.2 & 79.6\end{array}$ $\begin{array}{lllllllllllllllllllllllllll}\text { KC711053 } & 66.6 & 66.6 & 65.9 & 59 & 60.3 & 60.3 & 70.4 & 65.7 & 70.9 & 71.7 & 66.5 & 70.1 & 66.2 & 67.1 & 65.4 & 67 & 66.2 & 66 & 67.2 & 67.7 & 66.1 & 66.3 & 67.4 & 67.2 & 67.2\end{array}$ $\begin{array}{lllllllllllllllllllllllllllll}\text { AB693052 } & 67.2 & 67.2 & 67 & 59.1 & 59.4 & 59.4 & 68.6 & 64.5 & 68.7 & 65.1 & 66.3 & 72.7 & 65.6 & 68.3 & 66.2 & 67.5 & 66.3 & 66.7 & 66.8 & 68.5 & 66 & 67.7 & 67.9 & 66.6 & 67\end{array}$ $\begin{array}{llllllllllllllllllllllllllllll}\text { KP030761 } & 70 & 70 & 69.1 & 61.6 & 74 & 74 & 74.4 & 69.4 & 77.1 & 71.3 & 71.1 & 75.8 & 68.8 & 70.4 & 69.9 & 70.5 & 70.8 & 70.7 & 70.4 & 71.2 & 71.1 & 71 & 70 & 70.7 & 69.7\end{array}$ $\begin{array}{lllllllllllllllllllllllllll}\text { KJ725078 } & 65.2 & 65.2 & 63.2 & 57.2 & 58.8 & 58.8 & 70.1 & 64.6 & 66.6 & 67.6 & 63.5 & 68.1 & 65.2 & 65.4 & 63.2 & 64.4 & 64.2 & 64.3 & 64.1 & 64.6 & 63.2 & 63.8 & 64.8 & 64.7 & 64.8\end{array}$ $\begin{array}{lllllllllllllllllllllllllll}\text { KF264964 } & 66.7 & 66.7 & 67.5 & 57.9 & 59.9 & 59.9 & 68.5 & 65.2 & 69.4 & 67.1 & 68.1 & 73 & 66.1 & 67 & 67.1 & 68 & 67.3 & 67.1 & 68 & 68.9 & 67 & 67.3 & 68.4 & 67.2 & 67.2\end{array}$ $\begin{array}{llllllllllllllllllllllllllll}\text { AB693050 } & 66.9 & 66.9 & 66.7 & 59.5 & 60 & 60 & 69.1 & 65 & 68.6 & 65.5 & 66.5 & 73 & 66 & 68.2 & 66.7 & 67.2 & 66.4 & 66.7 & 66.8 & 68.8 & 66.4 & 67.8 & 68.3 & 66.4 & 66.6\end{array}$ $\begin{array}{llllllllllllllllllllllllllll}\text { MH300136 } & 59.1 & 59.1 & 57.5 & 51 & 50.8 & 50.8 & 60.2 & 56.8 & 61.4 & 61.9 & 57.6 & 59.9 & 59.5 & 58.5 & 57.4 & 56.8 & 56.3 & 55.8 & 56 & 60.7 & 56.5 & 56.9 & 59.3 & 56.1 & 58.1\end{array}$ $\begin{array}{lllllllllllllllllllllllllllll}\text { MF118774 } & 67.2 & 67.2 & 71.6 & 59.4 & 59.8 & 59.8 & 74.9 & 64.7 & 77.2 & 77 & 70.9 & 75.8 & 66.8 & 73.5 & 71 & 71.7 & 71.3 & 71.6 & 71.4 & 73.8 & 70.3 & 72 & 74.9 & 71.9 & 72\end{array}$ $\begin{array}{lllllllllllllllllllllllllll}\text { KY172846 } & 65.3 & 65.3 & 65.9 & 59.4 & 60.8 & 60.8 & 71.7 & 65.7 & 72 & 72.5 & 67.5 & 73.8 & 66 & 68.7 & 67.4 & 68.1 & 67.5 & 67.5 & 68.1 & 69.1 & 67.7 & 67.1 & 69 & 66.6 & 66.5\end{array}$ $\begin{array}{llllllllllllllllllllllllllll}\text { KJ849240 } & 66.3 & 66.3 & 67.6 & 58.1 & 61 & 61 & 71.4 & 66.6 & 71.3 & 68.7 & 68.2 & 75.1 & 66.5 & 68.4 & 67.6 & 69.1 & 67.9 & 67.9 & 69.4 & 68.1 & 67.6 & 67.6 & 68.8 & 68.6 & 68.8\end{array}$ $\begin{array}{llllllllllllllllllllllllllll}\mathrm{AB} 183747 & 66.3 & 66.3 & 66.3 & 58.1 & 59.8 & 59.8 & 68.6 & 64.6 & 68.9 & 65.5 & 66.5 & 71.8 & 65.4 & 68.2 & 66.4 & 66.4 & 66.1 & 65.8 & 65.1 & 67.8 & 65.5 & 67 & 65.5 & 66.1 & 66.2\end{array}$ $\begin{array}{lllllllllllllllllllllllllll}\text { KY172851 } & 65.7 & 65.7 & 66.1 & 59.3 & 60.4 & 60.4 & 71.2 & 65.5 & 71.4 & 72.1 & 67.1 & 72.2 & 66.2 & 68.6 & 67.1 & 67.7 & 67 & 66.9 & 68.1 & 68.8 & 67.1 & 66.7 & 68.7 & 66.2 & 66.4\end{array}$ $\begin{array}{lllllllllllllllllllllllllllll}\text { KP099967 } & 85.1 & 85.1 & 71.5 & 57.4 & 55.2 & 55.2 & 72.8 & 54.9 & 76 & 74.4 & 72.5 & 77.3 & 74.3 & 70.9 & 70.5 & 70.7 & 70.9 & 70 & 70.1 & 71.1 & 71 & 70.9 & 71.1 & 72.1 & 71.2\end{array}$ $\begin{array}{llllllllllllllllllllllllllllll}\text { MF582545 } & 69 & 69 & 71.1 & 60.1 & 57.2 & 57.2 & 67 & 63.2 & 67.7 & 66.5 & 71.6 & 69.6 & 72.5 & 71.4 & 70.5 & 71.5 & 71.6 & 71.8 & 71.4 & 70.9 & 70.9 & 71.5 & 68.8 & 71.7 & 72\end{array}$ $\begin{array}{lllllllllllllllllllllllllllll}\text { MN266293 } & 71.6 & 71.6 & 72.1 & 61.9 & 58.2 & 58.2 & 68.5 & 63.7 & 67.8 & 65.2 & 72.4 & 70.3 & 74.2 & 71.2 & 71.6 & 72.6 & 72.2 & 72.6 & 72.7 & 71.5 & 72.3 & 72.3 & 70.4 & 72.6 & 72.8\end{array}$ 


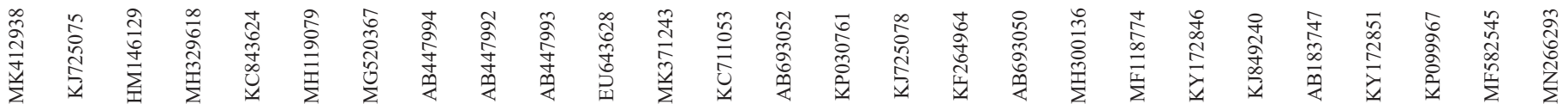

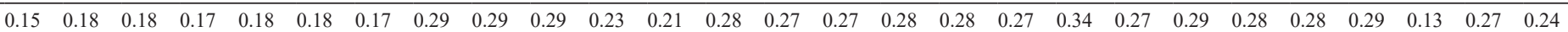

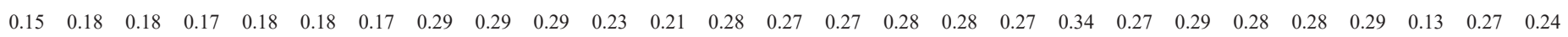

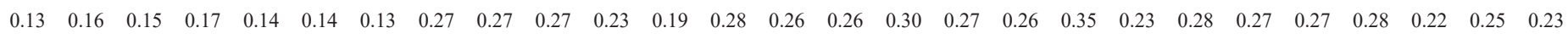

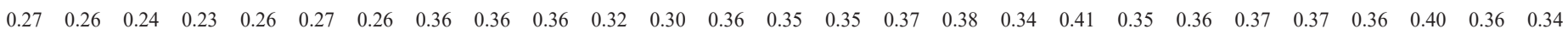

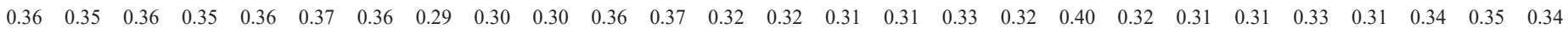

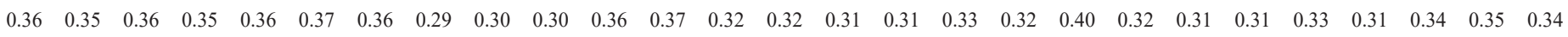

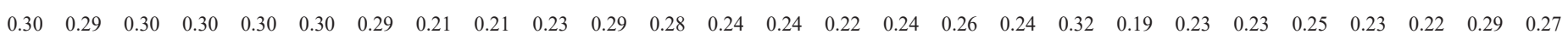

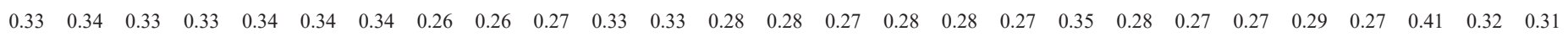

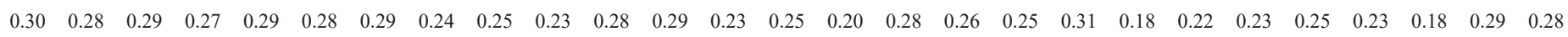

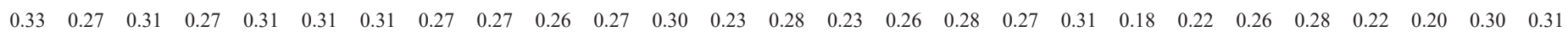

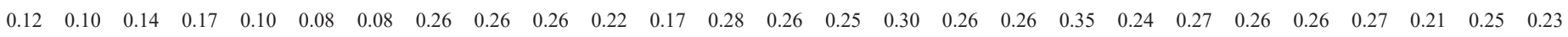

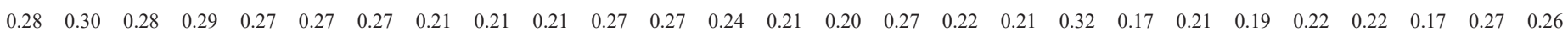

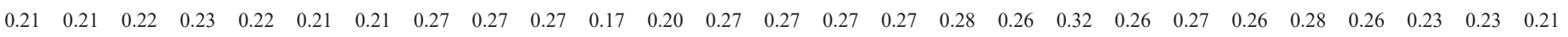

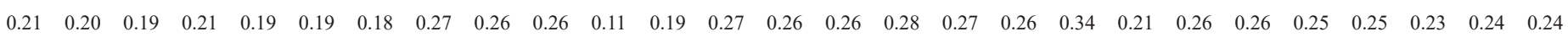

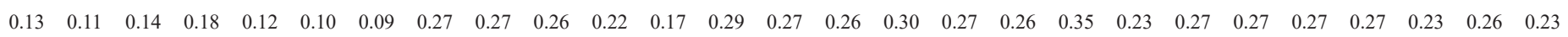

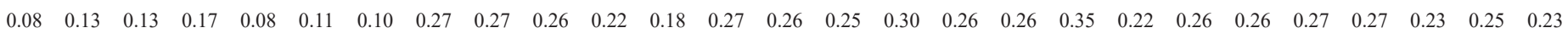

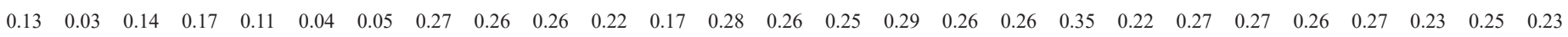

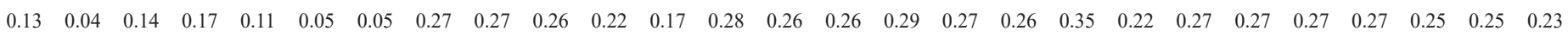

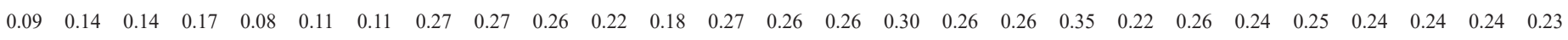

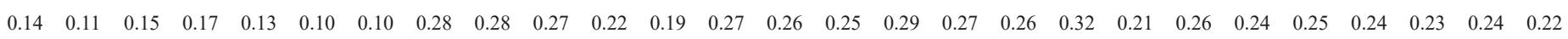

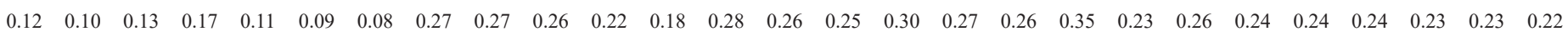

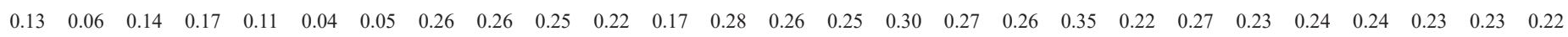

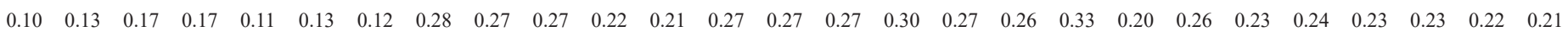

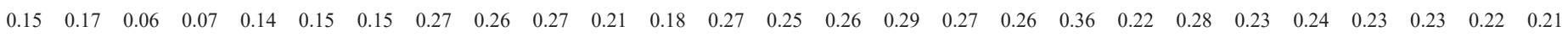

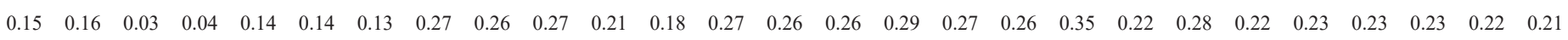

$\begin{array}{lllllllllllllllllllllllllllll}0.15 & 0.15 & 0.18 & 0.11 & 0.13 & 0.12 & 0.27 & 0.27 & 0.26 & 0.22 & 0.19 & 0.27 & 0.25 & 0.25 & 0.29 & 0.26 & 0.25 & 0.32 & 0.20 & 0.26 & 0.22 & 0.23 & 0.23 & 0.23 & 0.21 & 0.20\end{array}$

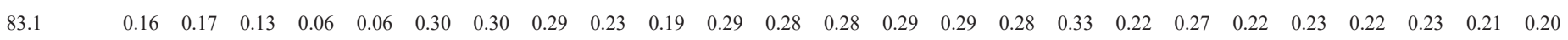

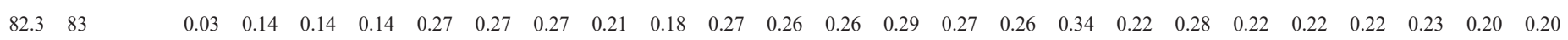

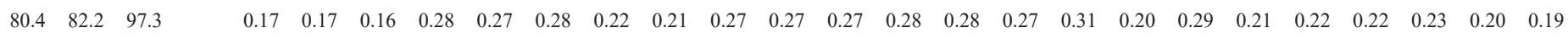

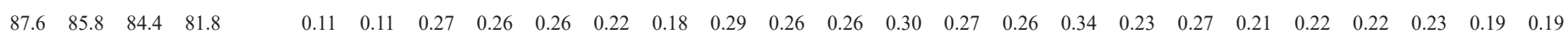

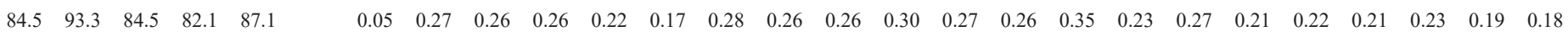

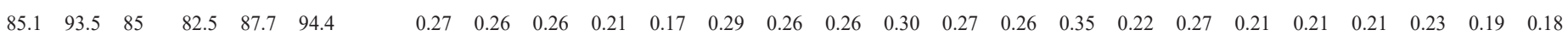

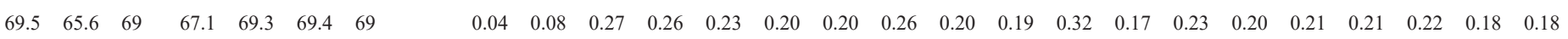

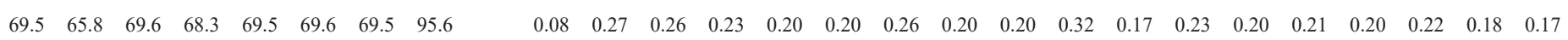

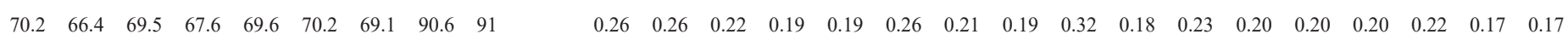

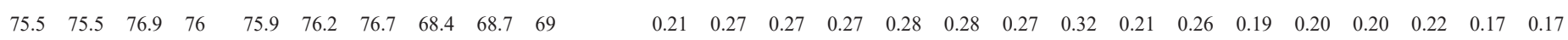

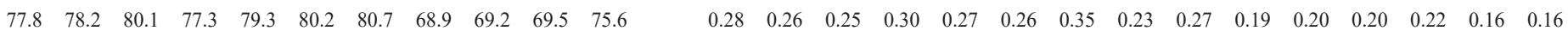

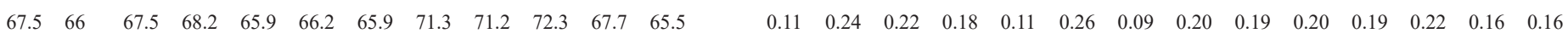

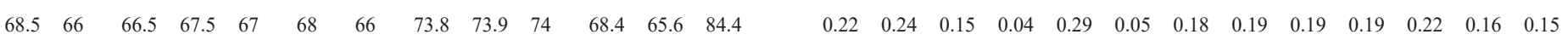

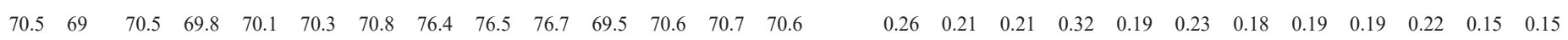

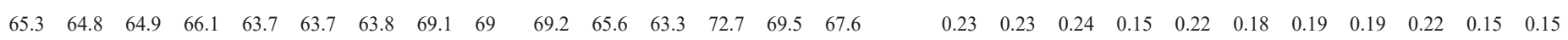

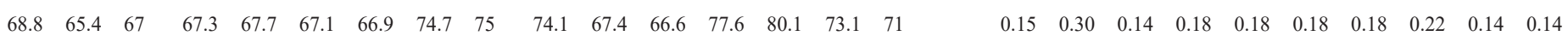

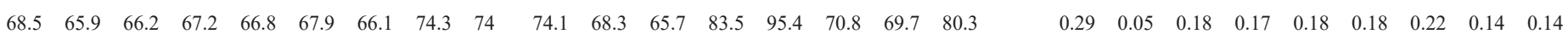

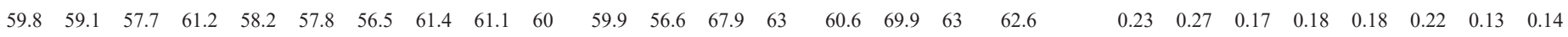

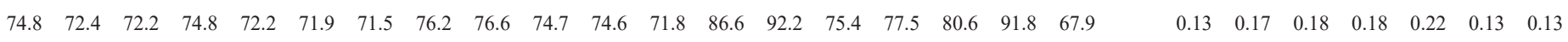

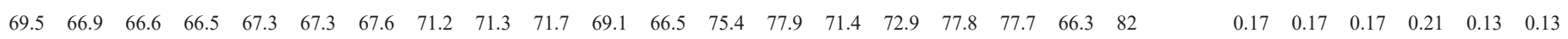

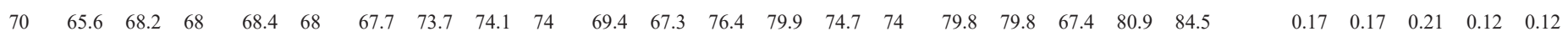

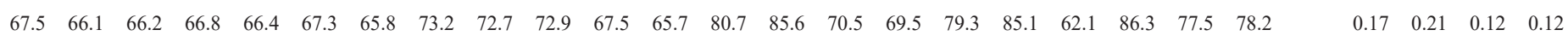

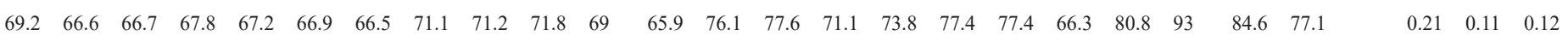

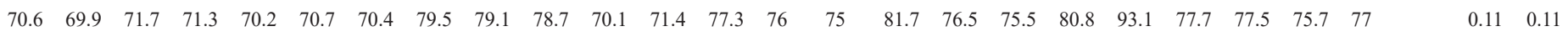

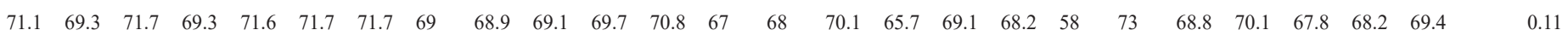
$\begin{array}{lllllllllllllllllllllllllll}71.7 & 70.7 & 72.9 & 70.7 & 72.4 & 72 & 72.2 & 69.6 & 69.6 & 69.4 & 70.4 & 71.4 & 68.9 & 69.8 & 71.1 & 66.8 & 70.4 & 70 & 58.7 & 74.6 & 68.7 & 70.7 & 69.6 & 68.7 & 72 & 77.4\end{array}$ 
(Supplementary table 2). M. barbi Tripathi, 1952 spores show differs from $M$. sophorae in having equal, small sized polar capsules and a intercapsular ridge while $M$. saranai (Tripathi, 1952) emend. Landsberg and Lom, 1991 spores are smaller in size and have unequal polar capsules as compare to M. sophorae. M. ampullaceus Lalita Kumari, 1969 have spores with oval, smaller sized with equal, flask shaped polar capsules and marked on posterior margin that clearly differentiates from M. sophorae. M. hyderabadense (Lalita Kumari 1969) emend. Gupta and Khera, 1988 spores differed from $M$. sophorae by pyriform shape, with narrow, pointed anterior end and 4-6 ridges at the posterior end with equal sized polar capsules with filament coils (8-9). Spores of M. indiae (Lalita Kumari 1969) emend. Gupta and Khera, 1988 also differed in having narrow, pointed anterior end with having 8-10 filament coils. M. koli have spores with small size, truncated anterior end in comparison to M. sophorae whereas M. osmaniae Lalita Kumari, 1969 shows marked differentiation with $M$. sophorae that comprises narrow, bent anterior end with 8-10 parietal folds on the posterior margin and polar capsules with prominent neck. M. pinnaurati Lalita Kumari, 1969 spores are smaller in size as compared to M. sophorae though M. karnatakae (Hagargi and Amoji, 1981) emend. Landsberg and Lom, 1991 spores are pyriform, larger in size with equal size polar capsules, having 6-7 filament coils that differentiated it from M. sophorae. M. sophorae can be readily distinguished from $M$. curmucae Seenappa and Manohar, 1980 in having spores more rounded anteriorly in comparison to it. M. mathuri Jayasri et al. 1981 comprises pointed anterior end with the slightly thick posterior end having 8-9 filament coils in large capsule and 3-4 coils in a smaller capsule as compared to $M$. sophorae. M. filamentosus Haldar et al. 1985 differentiated from M. sophorae (by slightly unequal capsules) as equal capsules are present in M. filamentosus. Spores of $M$. rohitae are smaller with a triangular notch at the anterior end and equal sized polar capsules that clearly recognize it from M. sophorae. M. saranae Gupta and Khera, 1990 differed in having small size spores and unequal polar capsules from M. sophorae. Besides the above, $M$. sophorae differed from other species as: M. ticto Sheeja and Janardanan, 2006 display different morphology by having 6-8 sutural folds in the posterior one-third of spore with equal polar capsules; while $M$. puntiusi Sheeja and Janardanan, 2006 clearly discriminate in morphology from $M$. sophorae by comprises 12 distinct sutural folds and two unequal polar capsules. Despite sharing some morphometric similarity M. chittalii Kaur and Singh, 2011 revealed a difference from $M$. sophorae having spores pear shaped with characteristic nipple-like anterior end, two equal polar capsules and a tongue shaped intercapsular process is also present. Spores of M. puntiusii Gupta and Kaur, 2017 significantly differed from $M$. sophorae with having one large and one smaller polar capsule. So, the present collected Myxobolus species was identified as M. sophorae based on the above mentioned characters.

Molecular analysis: Our 18S rDNA sequences of M. sophorae isolates (1260 and $1268 \mathrm{bp}$ ) shown to be most similar to $M$. ticto. No intraspecific divergence was found among the newly generated sequences from isolates of M. sophorae. Genetic p-distance comparison showed a sequence divergence of $M$. sophorae with $M$. ticto is $0.07 \%$ both found from the same fish genera Puntius.

\section{Phylogenetic analysis}

For the analysis, 18S rDNA sequences from isolates of $H$. namae and $M$. sophorae was analyzed in the present study. ML and BI analyses produced an identical topology; therefore, only the ML phylogenetic tree is presented here (Fig. 3). The phylogenetic tree inferred from ML and BI analyses shows that the sequences obtained in the current study of $H$. namae are nested within the lineage D1 in an independent branch with relatively high bootstrap and posterior probability support values (100/1) (Fig. 3). There is no interspecific sequence divergence was found among the two isolates of $H$. namae. Both isolates of $H$. namae are sister to the species that infected fish of the order Perciformes and one that infects Cypriniformes (KR704889). Lineage D1 comprises species all closely aligned with $H$. namae i.e., H. chaudhuryi (KT279402), Henneguya sp. RA-2015

\footnotetext{
Fig. 3. Phylogenetic relationship of H. namae and M. sophorae based on the $18 \mathrm{~S}$ gene sequences. Numbers at nodes indicates ML bootstrap values (1000 replications) and posterior probabilities (BI) respectively. Unsupported nodes by BI are marked with a hyphen. The scale bar indicates the number of substitution per site. Newly generated sequences in this study shown as bold. GenBank accession numbers are listed before the species names.
} 


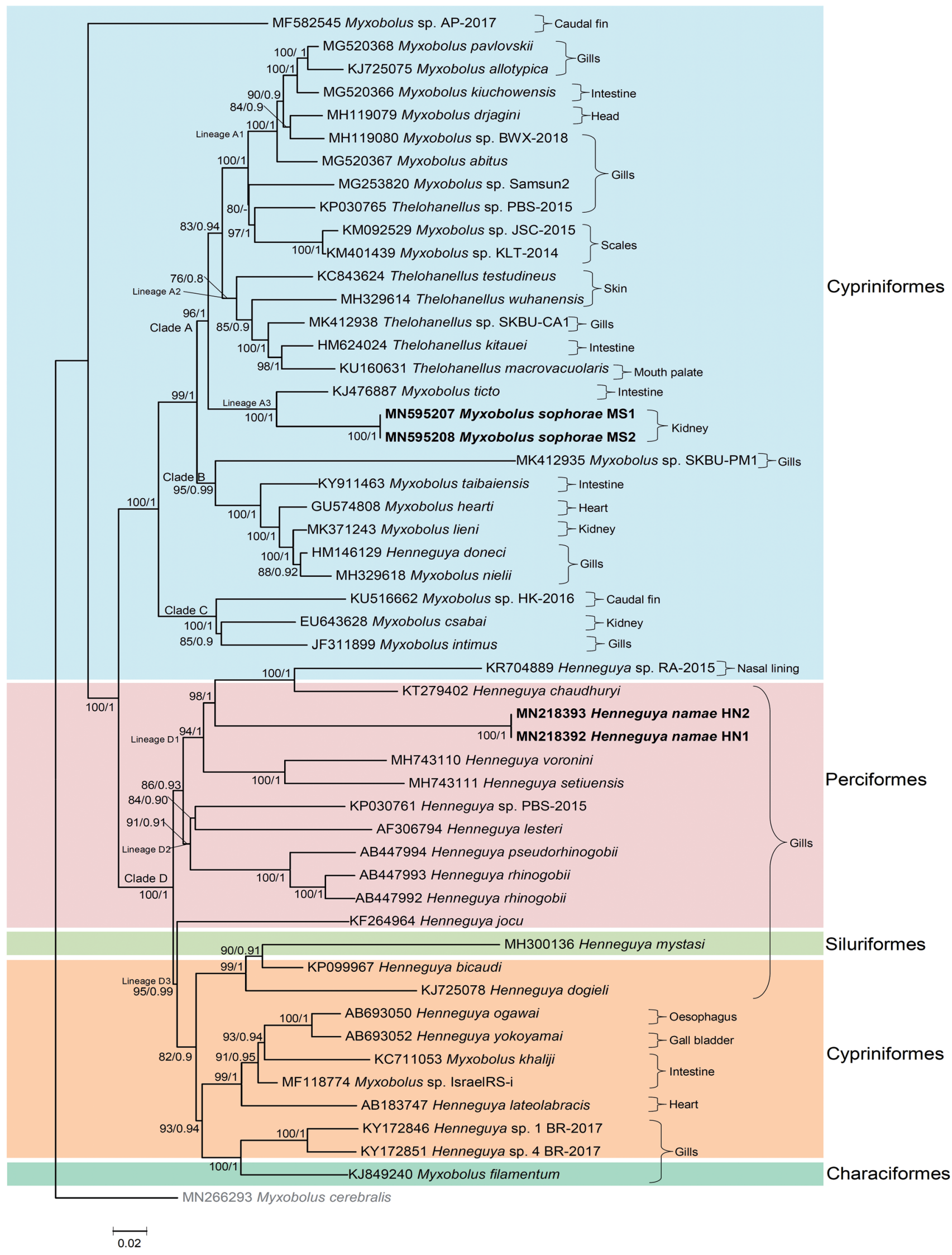


(KR704889) (78.0\%-76.4\%) from India and $H$. voronini (MH743110) and H. setiuensis (MH743111) from Malaysia (72.7\%-72.1\%) (Table 2). H. namae in clade D was also clustered with other species present in lineage D2: Henneguya sp. PBS-2015, H. lesteri, $H$. rhinogobii and $H$. pseudorhinogobii $(74.0 \%-75.5 \%)$ (Fig. 3, Table 2) which also presented for Perciformes infected hosts. Intraspecific sequence divergence based on $18 \mathrm{~S}$ dataset was ranging $0.21 \%$ (between $H$. namae and $H$. chaudhuryi), $0.23 \%$ between $H$. namae and Henneguya sp. RA-2015 while for $H$. namae with $H$. voronini and $H$. setiuensis was $0.24 \%$ (Fig. 3, Table 2 ). Phylogenetic tree of the 18S rDNA of the Myxobolus sophorae analyzed and showed a $90 \%$ similarity with the sequences of $M$. ticto (KJ476887) infecting the host Puntius ticto from India in a lineage A3 (Fig. 3). There is no interspecific sequence divergence was found among the two isolates of M. sophorae. Other Myxobolus species Myxobolus puntusii HK-2016 (KU516662), Myxobolus sp. SKBU-PM1 (MK412935) and Myxobolus sp. AP-2017 (MF582545) also infecting Puntius sophore, the same host infected by $M$. sophorae form clades far from M. sophorae (Fig. 3). The 18S sequence divergence of $M$. sophorae with sister species $M$. ticto is $0.07 \%$. The intraspecific sequence divergence of $M$. sophorae was ranging $0.25 \%$ between $M$. sophorae and Myxobolus sp. HK-2016 and it was $0.27 \%$ between M. sophorae and Myxobolus sp. SKBU-PM1. Unfortunately, in comparison to the morphological description available for about 20 Myxobolus species from India, molecular data is limited to only few that currently available in the GenBank. The tree revealed wellsupported clade (100/1.00) for M. sophorae; however, all other Myxobolus species infecting Puntius species were dispersed in the separate groups (Fig. 3). In the tree (Fig. 3), the myxozoan species shows phylogenetic affinities to the fish host and mainly clustered according to the order of the fish host they belongs.

\section{DISCUSSION}

Among myxozoan, Henneguya Thélohan 1892 and Myxobolus Bütschli 1882 are the species rich genera and reported worldwide (Eiras 2002, Eiras et al. 2005, Lom and Dyková 2006, Eiras and Adriano 2012, Liu et al. 2018). However, from the family Myxobolidae, more than 150 species have been described in India and most of the Henneguya and Myxobolus species were recorded from the freshwater environment in India (Kalavati and Nandi 2007, Kaur et al. 2015, Gupta and Kaur 2017, Chaudhary et al. 2018, Ahmed et al. 2019, Chaudhary et al. 2019). Though, in comparing to the large number of species described, the molecular data is available only to a small percentage of them. In India, most of the Henneguya species were described on the basis of morphology alone; therefore, the status of Indian Henneguya spp. must be questioned. To avoid such situations, for a more valid identification of species, it can be attained with the help of molecular data. Till date, only 05 sequences (H. mystasi, H. chaudhuryi, H. bicaudi, Henneguya sp. 1 HK-2016 and Henneguya sp. RA-2015) are available on the Genbank database from Indian Henneguya species that shows the scarcity of data from this region. When isolates of $H$. namae was compared to $H$. chaudhuryi and Henneguya sp. RA-2015 (KR704889) so far as their molecular data is available, they were found to be closely related. In the comparison between $H$. namae with $H$. chaudhuryi and Henneguya sp. RA-2015, in addition to the morphological differences pointed out above, $18 \mathrm{~S}$ rDNA shows a difference of $0.21-0.23 \%$ respectively. While pairwise comparisons among sequences of $H$. namae with $H$. voronini and $H$. setiuensis were significantly revealed a difference of $0.24 \%$. The phylogenetic analysis performed by both methods ML and BI revealed that $H$. namae form a separate lineage D1 that comprising most of the species that infect hosts belonging to Perciformes including one from Cypriniformes (Henneguya sp. RA-2015 (KR704889). The lineage D1 compiled of four Henneguya species, three of them are parasites of hosts from India (H. namae, H. chaudhuryi and Henneguya sp. RA-2015) infecting the gills and nasal lining and two species $H$. voronini and $H$. setiuensis are gills infected parasites from Malaysia respectively. Clustering of parasites, according to the order of the host fish that involving parasites from different genera, Henneguya and Myxobolus species.

Besides the morphology, M. sophorae molecular comparison of the $18 \mathrm{~S}$ rDNA gene confirmed that this species differ from Myxobolus puntusii HK-2016 (KU516662), Myxobolus sp. SKBU-PM1 (MK412935) and Myxobolus sp. AP-2017 (MF582545) from same host $P$. sophore. In our study, the analyzed $M$. sophorae sequence shares clade with $M$. ticto, but significantly varied in morphology as well as genetically. Besides the above, it is difficult to relate the other species present in supplementary table 2 because there are no $18 \mathrm{~S}$ rDNA sequence data is available for them. In the both trees for 
$H$. namae and M. sophorae, if we see the phylogeny, it is represented that in comparison to the infection site, host group is more relevant ancient evolutionary factor during selection can be taken into consideration. Clustering of Henneguya species does not appear according to the infected tissue, might be due to reasons of that molecular data available for this genus worldwide contributes a small fraction as compare to their total diversity. Here, we can present the fact that host affinity is more important than tissue tropism as also reported previously for myxobolid species (Carriero et al. 2013, Moreira et al. 2014, Rocha et al. 2019). In general, the phylogenetic tree shows that in case of $H$. namae tree host affinity is stronger evolutionary signal, this contention is also supported by previous studies (Carriero et al. 2013, Moreira et al. 2014, Rocha et al. 2019). In case of $M$. sophorae phylogeny, species that formed tree infected several closely related fish species of order Cypriniformes as also mentioned in a recent study by Rocha et al. 2019.

However, future phylogenetic studies with addition of molecular data will demonstrate the accurate relationships of Henneguya species as well as other myxobolids in relation to tissue tropism, host affinity and aquatic environments. This is the first report of obtaining partial $18 \mathrm{~S}$ rDNA sequence of $H$. namae and $M$. sophorae that contributes to the molecular data of Indian myxobolid species and will be helpful to evaluate the risk and to make possible management of severe infection.

Acknowledgements. The authors would like to thank Head, Department of Zoology, Chaudhary Charan Singh University, Meerut (U.P.), India, for laboratory facilities. This work was supported by a grant from Chaudhary Charan Singh University to first author as Research Grant for Ph.D. students. The authors declare that they have no conflict of interest.

\section{REFERENCES}

Ahmed I., Ahmad I., Dar S., Awas M., Kaur H., Ganai A., Amin B. (2019) Myxobolus himalayaensis sp. nov. (Cnidaria: Myxozoa) parasiting Schizothorax richardsonii (Cyprinidae: Schizothoracinae) from River Poonch in North West Himalaya, India. Aquacult. Rep. 14. DOI: 10.1016/j.aqrep.2019.100192

Bajpai R. N., Haldar D. P. (1982) A new myxosporidian, Unicauda chaudhuryi n. sp., (Myxozoa: Myxosporea) from the fish, Ophiocephalus punctata Bloch. Riv. Parassitol. 43: 147-152

Bala R. (2015) Taxonomic evaluation of myxozoan parasites infecting fresh water fish in Punjab. Unpublished Ph.D. thesis submitted to Department of Zoology and Environment Science, Punjabi University, Patiala, pp. 262

Barta J. R., Martin D. S., Libetator P. A., Dashkevicz M., Anderson J. W., Feighner S. D., Elbrecht A., Perkins-Barrow A., Jenkins
M. C., Danforth H. D., Ruff M. D., Profous-Juchelka H. (1997) Phylogenetic relationships among eight Eimeria species infecting domestic fowl inferred using complete small subunit ribosomal DNA sequences. J. Parasitol. 83: 262-271

Carriero M. M., Adriano E. A., Silva M. R. M., Ceccarelli P. S., Maia A. A. M. (2013) Molecular phylogeny of the Myxobolus and Henneguya genera with several new South American species. PLos One 8: e73713. DOI:10.1371/journal.pone.00737131-12

Chakravarty M. M. (1939) Studies on myxosporidia from fishes of Bengal, with a note on myxosporidian infection in aquaria fishes. Arch. Protistenkunde 92: 169-178

Chaudhary A., Goswami U., Gupta A., Cech G., Singh H.S., Molnár K., Székely C., Sharma B. (2018) Morphological, histological, and molecular description of Myxobolus ompok n. sp. (Myxosporea: Myxobolidae), a kidney myxozoan from Pabdah catfish Ompok pabda (Hamilton, 1822) (Siluriformes: Siluridae) in India. Parasitol. Res. 117: 1899-1905. DOI:10.1007/s00436018-5882-y

Chaudhary A., Gupta A., Goswami U., Cech G., Molnár K., Singh H. S., Székely C. (2019) Myxobolus cylindricus and Henneguya mystasi (Myxosporea: Myxobolidae) infecting two Indian fish species, Channa gachua and Mystus vittatus, respectively. Acta Parasitol. 64: 129-137. DOI: 10.2478/s11686-018-00014-8

Choudhury T. G., Singh S. K., Baruah A., Das A., Parhi J., Bhattacharjee P., Biswas P. (2015) Reproductive features of Puntius sophore (Hamilton 1822) from rivers of Tripura, India. Fishery Technology 52: 140-144

Eiras J. C. (2002) Synopsis of the species of the genus Henneguya Thélohan, 1892 (Myxozoa: Myxosporea: Myxobolidae). Syst. Parasitol. 52: 43-54

Eiras J. C., Adriano E. A. (2012) A checklist of new species of Henneguya Thélohan, 1892 (Myxozoa: Myxosporea, Myxobolidae) described between 2002 and 2012. Syst. Parasitol. 83: 95-104. DOI:10.1007/s11230-012-9374-7

Eiras J. C., Molnar K., Lu Y. S. (2005) Synopsis of the species of Myxobolus Bütschli, 1882 (Myxozoa: Myxosporea: Myxobolidae). Syst. Parasitol. 61: 1-46. DOI:10.1007/s11230-004-63439

Eiras J. C., Zhang J., Molnár K. (2014) Synopsis of the species of Myxobolus Bütschli, 1882 (Myxozoa: Myxosporea, Myxobolidae) described between 2005 and 2013. Syst. Parasitol. 88: 11-36. DOI:10.1007/s11230-014-9484-5

Eszterbauer E., Székely C. (2004) Molecular phylogeny of the kidney parasitic Sphaerospora renicola from common carp (Cyprinus carpio) and Sphaerospora sp. from goldfish (Carassius auratus auratus). Acta Vet. Hung. 52: 469-478. DOI:10.1556/ AVet.52.2004.4.9

Gupta A., Kaur H. (2017) Morphological and molecular characterization of Myxobolus puntiusii n. sp. (Cnidaria: Myxosporea) infecting Puntius sophore Hamilton, 1822 from Ranjit Sagar Wetland, Punjab (India). Turk. J. Zool. 41: 791-799

Gupta S., Khera S. (1988) Review of the genus Myxobolus Butschli, 1882. Res. Bull. (Science), Punj. Univ. 39: 45-48

Gupta S., Khera S. (1990) On three species of the genus Myxobolus Butschli, 1882 (Myxozoa: Myxosporea) from freshwater fishes of northern India. Indian J. Parasitology 14: 1-8

Hagargi S. S., Amoji S. D. (1981) Myxosoma karnatakae n. sp. (Protozoa: Myxosporidia) from the caudal muscles of fresh water teleost fish, Barbus chola (Ham. et Buch.). Arch. Protistenk. 124: $385-390$

Haldar D. P., Das M. K., Sharma B. K. (1983) Studies on Protozoan parasites from fishes. Four new species of the genera 
Henneguya Thelohan, 1882, Thelohanellus Kudo, 1933 and Myxobolus Butschli, 1882. Arch. Protistenk. 127: 283-296

Haldar D. P., Mukherjee M. (1985) Studies on Bivalvulida (Myxozoa: Myxosporea): Observations on two new species of Henneguya from food fishes of West Bengal, India. Arch. Protistenk. 130: 419-425

Hall T. A. (1999) BioEdit: a user-friendly biological sequence alignment editor and analysis program for Windows 95/98/NT. Nucleic Acids Sympos. Ser. 41: 95-98

Hallett S. L., Diamant A. (2001) Ultrastructure and small subunit ribosomal DNA sequence of Henneguya lesteri n. sp. (Myxosporea), a parasite of sand whiting Sillago analis (Sillaginidae) from the coast of Queensland, Australia. Dis. Aquat. Organ. 46: 197-212. DOI: $10.3354 /$ dao046197

Jayasri M. (1982) Morphology and pathology of Myxobolus sophorae $\mathrm{n}$. sp. Proceedings of the Indian Academy of Parasitology 3: $1-3$

Jayasri M., Parvateesam M., Mathur P. N. (1981) Myxosoma mathurii n. sp., (Protozoa: Myxosporidia) parasitic on Puntius sarana. Curr. Sci. 50: 736-739

Kalavati C., Nandi N. C. (2007) Handbook on myxosporean parasites of Indian fishes. New Delhi: Zoological Survey of India, Kolkata, India, pp. 294

Kaur H., Katoch A., Dar S. A., Singh R. (2015) Myxobolus nanokiensis sp. nov. (Myxozoa: Bivalvulidae), a new pathogenic myxosporean parasite causing haemorrhagic gill disease in cultured Indian major carp fish, Labeo rohita (Hamilton 1822) in Punjab, India. J. Parasit. Dis. 39: 405-413. DOI:10.1007/ s12639-013-0351-0

Kaur H., Singh R. (2011) Two new species of Myxobolus (Myxozoa: Myxosporea: Bivalvulida) from freshwater fishes of Punjab Wetlands (India). J. Parasit. Dis. 35: 33-41. DOI:10.1007/ s12639-011-0024-9

Kumar S., Stecher G., Tamura K. (2016) MEGA7: Molecular Evolutionary Genetics Analysis Version 7.0 for Bigger Datasets. Mol. Biol. Evol. 33: 1870-4. DOI:10.1093/molbev/msw054

Lalitha Kumari P. S. (1965) On a new species of Henneguya (Protozoa: Myxosporidia) from an Indian fresh water fish, Ophiocephalus gachua. Riv. Parassitol. 26: 79-84

Lalitha Kumari P. S. (1969) Studies on parasitic protozoa (Myxosporidia) of fresh water fishes of Andhra Pradesh, India. Riv. Parassitol. 30: 153-226

Landsberg J. H., Lom J. (1991) Taxonomy of the genera of the Myxobolus/Myxosoma group (Myxobolidae: Myxosporea), current listing of the species and revision of synonyms. Syst. Parasitol. 18: $165-186$

Liu X. H., Xu L.W., Luo D., Zhao Y. L., Liu G. F., Zhang Q. Q., Zhang J. Y. (2018) Henneguya ovata n. sp. (Myxosporea: Bivalvulida), causing severe enteric henneguyosis of net-cage-cultured ovate pompano, Trachinotus ovatus in China. Aquaculture 483: 8-15. DOI:10.1016/j.aquaculture.2017.10.009

Lom J., Arthur J. R. (1989) A guideline for preparation of species description in Myxosporea. J. Fish Dis. 12: 151-156. DOI:10.1111/j.1365-2761.1989.tb00287.x

Lom J., Dyková I. (2006) Myxozoan genera: definition and notes on taxonomy, life-cycle terminology and pathogenic species. Folia Parasitol. 53: 1-36. DOI: 10.14411/fp.2006.001

Milne I., Lindner D., Bayer M., Husmeier D., McGuire G., Marshall D. F., Wright F. (2009) TOPALi v2: as rich graphical interface for evolutionary analyses of multiple alignments on HPC clusters and multi-core desktops. Bioinformatics 25: 126-127. DOI:10.1093/bioinformatics/btn575
Mohanty B. P., Pati M. K., Bhattacharjee S., Hajra A., Sharma A. P. (2013) Small indigenous fishes and their importance in human health. Advances in Fish Research 5: 257-278

Molnár K. (2002) Site preference of fish myxosporeans in the gill. Dis. Aquat. Org. 48: 197-207. DOI:10.3354/dao048197

Moreira G. S. A, Adriano E. A., Silva M. R. M., Ceccarelli P. S., Maia A. A. M. (2014) The morphological and molecular characterization of Henneguya rotunda $\mathrm{n}$. sp., a parasite of the gill arch and fins of Salminus brasiliensis from the Mogi Guaçu River, Brazil. Parasitol. Res. 113: 1703-1711. DOI:10.1007/s00436014-3815-y

Okamura B., Gruhl A., Reft A. J. (2015) Cnidarian origins of the Myxozoa. In: Myxozoan evolution, ecology and development, (Eds. B. G. B Okamura, J. L. Bartholomew). Cham, Heidelberg, New York, Dordrecht, London: Springer International Publishing AG, 45-68

Posada D. (2008) JModelTest: phylogenetic model averaging. Mol. Biol. Evol. 25: 1253-1256. DOI:10.1093/molbev/msn083

Qadri S. S. (1965) Study on a new myxosporidian parasite from the fresh water fish Notopterus notopterus. Zool. Anz. 175: 225-228

Rocha S., Azevedo C., Oliveira E., Alves Â., Antunes C., Rodrigues P., Casal G. (2019) Phylogeny and comprehensive revision of mugiliform-infecting myxobolids (Myxozoa, Myxobolidae), with the morphological and molecular redescription of the cryptic species Myxobolus exiguus. Parasitology 146: 479-496. DOI:10.1017/S003118201800167

Roos N., Islam M. M., Thilsted S. H. (2003) Small Indigenous Fish Species in Bangladesh: Contribution to Vitamin A, Calcium and Iron Intakes. The Journal of Nutrition 133: 4021-4026. DOI:10.1093/jn/133.11.4021S

Seenappa D., Manohar L. (1980) Two new species of Myxobolus (Myxoporidea: Protozoa) parasitic on Cirrhina mrigala (Ham.) and Puntius curmuca (Hamilton). Curr. Sci. 49: 204-206

Seenappa D., Manohar L., Prabhu R. M. (1981) Henneguya thermalis n. sp. parasitic in the brain tissue of the loach, Lepidocephalichthys thermalis (Ham.). Curr. Sci. 50: 295-296

Sheeja P. K., Janardanan K. P. (2006) Two new myxosporean parasites (Myxozoa; Myxobolidae) from the freshwater fish Puntius ticto punctatus Day in Kerala, India. Zoos Print Journal 22: $2527-2530$

Székely C., Cech G., Chaudhary A., Borzak R., Singh H. S., Molnár K. (2015) Myxozoan infections of the three Indian major carps in fish ponds around Meerut, UP, India, with descriptions of three new species, Myxobolus basuhaldari sp. n., M. kalavatiae sp. n. and $M$. meerutensis sp. n., and the redescription of M. catlae and M. bhadrensis. Parasitol. Res. 114: 1301-11. DOI:10.1007/s00436-014-4307-9

Thompson J. D., Higgins D. G., Gibson T. J. (1994) CLUSTAL $\mathrm{W}$ : improving the sensitivity of progressive multiple sequence alignment through sequence weighting, position-specific gap penalties and weight matrix choice. Nucleic Acids Res. 22: 4673-4680

Tripathi Y. R. (1952) Studies on the parasites of Indian fishes. I. Protozoa: Myxosporidia together with a checklist of parasitic protozoa described from Indian fishes. Rec. Indian Mus. 50: 63-88

Received on $4^{\text {th }}$ January, 2019; revised on $7^{\text {th }}$ March, 2020; accepted on $24^{\text {th }}$, April, 2020 


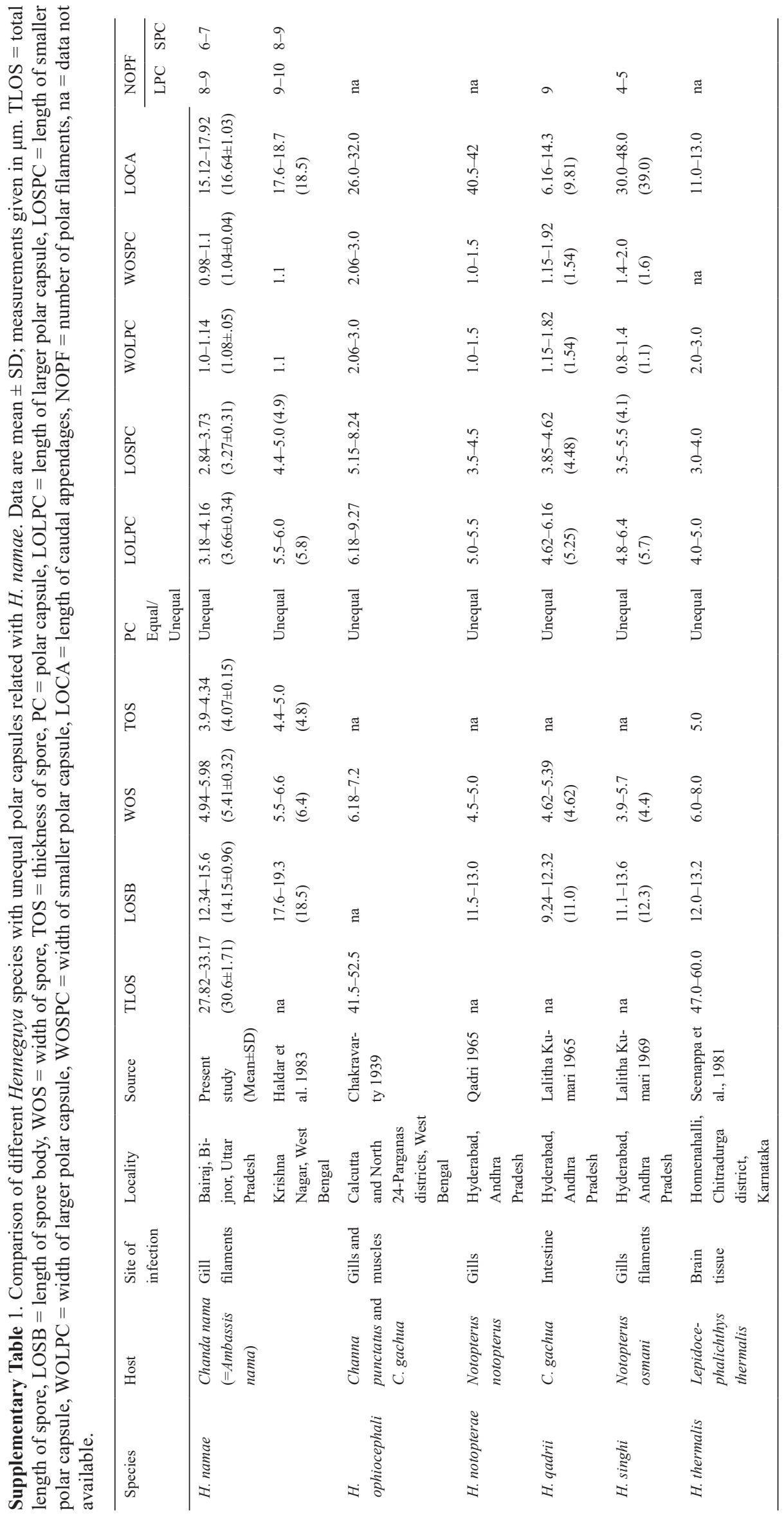


Supplementary Table 2. Comparison of Myxobolus species infected different species of Puntius from India with M. sophorae. Data are mean $\pm \mathrm{SD}$; measurements given in $\mu \mathrm{m}$. LOS $=$ length of spore, WOS $=$ width of spore, $\mathrm{TOS}=$ thickness of spore, $\mathrm{PC}=$ polar capsule, LOLPC $=$ length of larger polar capsule, LOSPC = length of smaller polar capsule, WOLPC $=$ width of larger polar capsule, WOSPC $=$ width of smaller polar capsule, $\mathrm{NOPF}=$ number of polar filaments, na $=$ data not available.

\begin{tabular}{|c|c|c|c|c|c|c|}
\hline Species & Host & Site of infection & Locality & Source & LOS & WOS \\
\hline \multirow[t]{2}{*}{$\begin{array}{l}\text { M. sophorae } \\
\text { Jayasri,1982 }\end{array}$} & Puntius sophore & Kidney & Meerut, Uttar Pradesh & $\begin{array}{l}\text { Present study } \\
(\text { Mean } \pm \text { SD })\end{array}$ & $14.0-15.1(14.57 \pm 0.33)$ & $10.4-11.4(10.91 \pm 0.34)$ \\
\hline & & Gills and kidney & $\begin{array}{l}\text { Parvatsar lake, } \\
\text { Rajasthan }\end{array}$ & Jayasri1982 & $6.4-26.6(14.9)$ & $5.9-10.1(7.7)$ \\
\hline $\begin{array}{l}\text { M. barbi Tripathi, } \\
1952\end{array}$ & P. ticto & Skin & $\begin{array}{l}\text { North 24-Parganas } \\
\text { district, West Bengal }\end{array}$ & Tripathi, 1952 & $12.6-13.5$ & 9.0 \\
\hline $\begin{array}{l}\text { M. saranai (Tripathi, } \\
\text { 1952) emend. Lands- } \\
\text { berg and Lom, } 1991\end{array}$ & P. sarana & Gills & $\begin{array}{l}\text { North 24-Parganas } \\
\text { district, West Bengal }\end{array}$ & $\begin{array}{l}\text { (Tripathi, 1952) } \\
\text { emend. Landsberg } \\
\text { and Lom, } 1991\end{array}$ & $6.4-7.0$ & $4.5-5.0$ \\
\hline $\begin{array}{l}\text { M. ampullaceus Lali- } \\
\text { tha Kumari, } 1969\end{array}$ & P. kolus & $\begin{array}{l}\text { Dorsal and ventral } \\
\text { fins }\end{array}$ & $\begin{array}{l}\text { Hyderabad, Andhra } \\
\text { Pradesh }\end{array}$ & Lalitha Kumari, 1969 & $8.6-10.7(9.8)$ & $6.4-7.9(7.1)$ \\
\hline $\begin{array}{l}\text { M. hyderabadense } \\
\text { (Lalitha Kumari } \\
\text { 1969) emend. Gupta } \\
\text { and Khera, 1988b }\end{array}$ & $\begin{array}{l}\text { P. pinnauratus, } P \text {. } \\
\text { filamentosus }\end{array}$ & Gill filaments & $\begin{array}{l}\text { Hyderabad city, } \\
\text { Andhra Pradesh; } \\
\text { Vellayani lake, Kerala }\end{array}$ & $\begin{array}{l}\text { (Lalitha Kumari } \\
\text { 1969) emend. Gupta } \\
\text { and Khera, 1988b }\end{array}$ & $9.3-11.5(10.1)$ & $5.0-8.0(5.9)$ \\
\hline $\begin{array}{l}\text { M. indiae (Lalitha } \\
\text { Kumari 1969) emend. } \\
\text { Gupta and Khera, } \\
\text { 1988b }\end{array}$ & P. sarana & Gill filaments & $\begin{array}{l}\text { Hyderabad city, and } \\
\text { Warangal, Warangal } \\
\text { districts, Andhra } \\
\text { Pradesh }\end{array}$ & $\begin{array}{l}\text { (Lalitha Kumari } \\
\text { 1969) emend. Gupta } \\
\text { and Khera, 1988b }\end{array}$ & $12.4-15.0(13.7)$ & $6.4-8.6(7.3)$ \\
\hline $\begin{array}{l}\text { M. koli Lalitha Ku- } \\
\text { mari, } 1969\end{array}$ & $\begin{array}{l}\text { P. kolus, } \\
\text { P. filamentosus }\end{array}$ & $\begin{array}{l}\text { Dorsal and ventral } \\
\text { fins }\end{array}$ & $\begin{array}{l}\text { Hyderabad city, } \\
\text { Andhra Pradesh; Vel- } \\
\text { layani lake, Kerala }\end{array}$ & Lalitha Kumari, 1969 & $7.1-9.6(8.4)$ & $5.0-6.4(6.0)$ \\
\hline $\begin{array}{l}\text { M. osmaniae Lalitha } \\
\text { Kumari, } 1969\end{array}$ & P. punjabensis & Liver and intestine & $\begin{array}{l}\text { Hyderabad city, } \\
\text { Andhra Pradesh }\end{array}$ & Lalitha Kumari, 1969 & $12.4-15.0(13.5)$ & $7.1-10.0(8.6)$ \\
\hline $\begin{array}{l}\text { M. pinnaurati Lalitha } \\
\text { Kumari, } 1969\end{array}$ & P. pinnauratus & Gill filaments & $\begin{array}{l}\text { Lake near Hyderabad } \\
\text { city, Andhra Pradesh }\end{array}$ & Lalitha Kumari, 1969 & $8.0-11.4(9.6)$ & $6.5-7.9(7.0)$ \\
\hline $\begin{array}{l}\text { M. karnatakae } \\
\text { (Hagargi and Amoji, } \\
\text { 1981) emend. Lands- } \\
\text { berg and Lom, } 1991\end{array}$ & P. chola & Caudal muscles & Gulburga, Karnataka & $\begin{array}{l}\text { (Hagargi and Amoji, } \\
\text { 1981) emend. Lands- } \\
\text { berg and Lorn, } 1991\end{array}$ & $16.32-19.04(17.58)$ & $10.88-13.6(11.1)$ \\
\hline $\begin{array}{l}\text { M. curmucae Seenap- } \\
\text { pa and Manohar, } \\
\text { 1980a }\end{array}$ & P. сигтиса & Below the scales & $\begin{array}{l}\text { Nethravathi River, } \\
\text { Bantwal, Karnataka }\end{array}$ & $\begin{array}{l}\text { Seenappa and Mano- } \\
\text { har } 1980\end{array}$ & $8.0-11.0(9.8)$ & $7.0-8.0(7.6)$ \\
\hline $\begin{array}{l}\text { M. mathuri Jayasri et } \\
\text { al., } 1981\end{array}$ & P. sarana & Gills & $\begin{array}{l}\text { Parvatsar Lake, } \\
\text { Rajasthan }\end{array}$ & Jayasri et al., 1981 & $8.7-23.5$ & $5.1-10.1$ \\
\hline $\begin{array}{l}\text { M. filamentosus Hal- } \\
\text { dar et al., } 1985\end{array}$ & P. filamentosa & Cartilage and brain & $\begin{array}{l}\text { Kalyani, Nadia dis- } \\
\text { trict, West Bengal }\end{array}$ & Haldaret et al. 1985 & $11.2-17.3(13.7)$ & $8.1-12.2(9.5)$ \\
\hline $\begin{array}{l}\text { M. rohitae Haldar et } \\
\text { al., } 1983\end{array}$ & P. sarana & Scales & $\begin{array}{l}\text { Krishna nagar, West } \\
\text { Bengal; } \\
\text { Harike, Nangal, Ro- } \\
\text { par, Ludhiana, Punjab }\end{array}$ & Haldar et al., 1983 & $9.9-12.1(10.6)$ & $8.8-9.9(9.0)$ \\
\hline $\begin{array}{l}\text { M. saranae Gupta and } \\
\text { Khera, } 1990\end{array}$ & P. sarana & Gills & $\begin{array}{l}\text { Ropar and Ludhiana, } \\
\text { Punjab }\end{array}$ & $\begin{array}{l}\text { Gupta and Khera, } \\
1990\end{array}$ & $6.0-9.0(7.72)$ & $6.0-7.0(6.2)$ \\
\hline $\begin{array}{l}\text { M. ticto Sheeja and } \\
\text { Janardanan, } 2006\end{array}$ & P. ticto punctatus & $\begin{array}{l}\text { Gills, muscles, intes- } \\
\text { tine and liver }\end{array}$ & Malappuram, Kerala & $\begin{array}{l}\text { Sheeja and Janardan- } \\
\text { an } 2006\end{array}$ & $12.75-15(14.55)$ & $7.75-9.0(7.8)$ \\
\hline $\begin{array}{l}\text { M. chittalii Kaur and } \\
\text { Singh, } 2011\end{array}$ & P. sophore & Gill lamellae & $\begin{array}{l}\text { Harike Wetland, } \\
\text { Punjab }\end{array}$ & Kaur and Singh 2011 & $8.8-9.2(9.0 \pm 0.28)$ & $5.88-6.48(6.18 \pm 0.42)$ \\
\hline $\begin{array}{l}\text { M. puntusii Gupta and } \\
\text { Kaur, } 2017\end{array}$ & P. sophore & Caudal fin & $\begin{array}{l}\text { Ranjit Sagar Wetland, } \\
\text { Punjab }\end{array}$ & Gupta and Kaur 2017 & $7.56-7.96(7.76 \pm 0.28)$ & $5.25-5.47(5.36 \pm 0.15)$ \\
\hline
\end{tabular}




\begin{tabular}{|c|c|c|c|c|c|c|c|}
\hline \multirow[t]{2}{*}{ TOS } & \multirow{2}{*}{$\begin{array}{l}\text { PC Equal } \\
\text { /Unequal }\end{array}$} & \multirow[t]{2}{*}{ LOLPC } & \multirow[t]{2}{*}{ LOSPC } & \multirow[t]{2}{*}{ WOLPC } & \multirow[t]{2}{*}{ WOSPC } & \multicolumn{2}{|l|}{ NOPF } \\
\hline & & & & & & Large & Small \\
\hline $6.2-7.4(6.91 \pm 0.39)$ & Slightly unequal & $5.72-6.5(6.04 \pm 0.27)$ & $4.94-6.14(5.48 \pm 0.34)$ & $2.6-3.2(2.89 \pm 0.22)$ & $2.34-3.12(2.69 \pm 0.24)$ & $5-6$ & $5-6$ \\
\hline na & Equal or unequal & na & na & na & na & na & na \\
\hline na & Equal & $3.6-4.5$ & & 2.7 & & na & \\
\hline na & Unequal & 3.5 & 1.5 & 1.5 & 1.0 & na & \\
\hline & Equal & $5-6.4(5.8)$ & & $2.5-2.9(2.8)$ & & $5-6$ & \\
\hline na & Equal & $5.0-7.3(5.8)$ & & $1.4-3.0(2.2)$ & & $8-9$ & \\
\hline na & Unequal & $5.7-7.1(5.9)$ & $5.0-6.4(5.2)$ & $1.4-2.5(2.1)$ & $1.4-2.5(2.1)$ & $8-10$ & $8-10$ \\
\hline na & Unequal & $3.9-4.6(4.3)$ & $1.4-2.1(2.0)$ & $2.1-3.1(2.8)$ & $0.7-1.4(1.2)$ & $5-6$ & \\
\hline na & Unequal & $5.0-7.1(5.6)$ & $2.1-3.6(2.6)$ & $2.0-3.9(3.2)$ & $1.4-2.9(2.5)$ & $5-6$ & $5-6$ \\
\hline na & Unequal & $3.6-6.4(4.4)$ & $2.9-5.0(3.1)$ & $1.1-2.1(1.9)$ & $1.1-2.1(1.6)$ & & \\
\hline na & Equal & $7.3-10.88(11.11)$ & & $3.58-5.44(4.78)$ & & $6-7$ & \\
\hline $5.0-6.0(5.3)$ & $\begin{array}{l}\text { Equal, rarely slightly } \\
\text { unequal }\end{array}$ & $4.5-5.0(4.9)$ & $3.0-4.0(3.9)$ & $2.0-3.0(2.5)$ & $2.0-3.0(2.4)$ & na & na \\
\hline na & Unequal & $2.7-11.9$ & $2.7-7.8$ & $1.8-4.6$ & $1.8-4.6$ & $8-9$ & $3-4$ \\
\hline $5.0-6.0(5.20)$ & Unequal or equal & $4.0-7.1(3.6)$ & & $2.0-4.0(3.1)$ & & $5-6$ & \\
\hline na & Equal & 6.6 & & 3.3 & & $5-6$ & \\
\hline na & Unequal & $4.0-5.0(4.24)$ & $1.5-3.0(1.98)$ & $2.5-4.0(3.04)$ & $1.0-2.0(1.3)$ & na & \\
\hline na & Equal & $4.7-7.5(6.63)$ & & $2.25-3.0(2.92)$ & & $6-8$ & \\
\hline na & Equal & $4.0-5.0(4.5 \pm 0.70)$ & & $2.0-2.8(2.4 \pm 0.56)$ & & $4-5$ & \\
\hline na & Unequal & $2.95-3.07(3.0 \pm 0.08)$ & $1.60-1.82(1.71 \pm 0.15)$ & $1.75-1.91(1.83 \pm 0.11)$ & $0.89-0.99(0.94 \pm 0.07)$ & $6-7$ & $3-4$ \\
\hline
\end{tabular}

